\title{
Neuronal Characterization, Compartmental Distribution, and Activity-dependent Regulation of Glutamate Immunoreactivity in Adult Monkey Striate Cortex
}

\author{
Renee K. Carder and Stewart H. C. Hendry ${ }^{a}$ \\ Department of Anatomy and Neurobiology, University of California at Irvine, Irvine, California 92717
}

Monospecific antibodies to glutamate were used to characterize the organization of excitatory neurons and the plasticity of glutamate expression in the macaque striate cortex. Somata and processes immunoreactive for glutamate were densely and unevenly distributed in layers II-III, IVA, IVC. In tangential sections through layers II and III, patches of intense glutamate immunostaining were observed and were found to coincide with regions of the cytochrome oxidase (CO)-rich puffs. By contrast, clusters of intense immunostaining were surrounded by the lightly immunostained but intensely CO-stained lattice in layer IVA. Similarly, in layer IVC, focal aggregates of intense glutamate immunoreactivity were interspersed among regions of light immunostaining but intense $\mathrm{CO}$ staining. Glutamate immunoreactivity was also intense in layer VI but was much lighter in layers I, IVB, and $V$. Throughout the striate cortex, neurons resembling pyramidal cells and spiny stellate cells and processes that included dendrites and axons were immunostained. None of the glutamate-positive neurons was GABA immunoreactive. Following monocular deprivation of adult monkeys by intravitreal injections of TTX into one eye, glutamate immunoreactivity in layers IVC was distributed in alternating intensely and lightly stained stripes. The stripes of reduced immunostaining, which contained an abnormally low concentration of glutamate neurons and pale neuropil, corresponded to columns dominated by the TTX-injected eye. Similar stripes of alternating intense and light immunoreactivity were seen in layers II-III, where they corresponded to rows of puffs at the centers of intact-eye and deprived-eye columns, respectively. These findings demonstrate that glutamate-immunoreactive neurons and terminals in monkey striate cortex are densely concentrated in layers receiving direct geniculocortical innervation. In addition, the glutamate neurons and termimals form discrete units, which in layers II and III coincide precisely with regions receiving geniculocortical terminations but in layers IVA are segregated from these terminations. The findings also indicate that glutamate immunoreactivity is regulated by visually driven activity, and

\footnotetext{
Received Nov. 17, 1992; revised June 24, 1993; accepted June 30, 1993.

This work was supported by Grants EY 06344 (R.K.C.), EY 06432 (S.H.C.H.), and EY 07193 to Dr. E. G. Jones from the National Institutes of Health, United States Public Health Service.

Correspondence should be addressed to Dr. Renee K. Carder, Department of Psychology, University of California at Los Angeles, Los Angeles, CA 90024

a Present address: Zanvyl Krieger Mind/Brain Institute and Department of Neuroscience, 338 Krieger Hall, Johns Hopkins University, 3400 N. Charles Street Baltimore, MD 21218.

Copyright (C) 1994 Society for Neuroscience $0270-6474 / 94 / 140242-21 \$ 05.00 / 0$
}

suggest that monocular deprivation in adulthood leads to a reduction in the major excitatory neurotransmitter in visual cortex as well as previously indicated reductions in GABA, the major inhibitory neurotransmitter.

[Key words: pyramidal cells, neuronal plasticity, excitatory neurotransmitter, spiny stellate cells, neurotransmitter regulation, visual cortex I

Two major classes of excitatory ncurons dominate the circuitry of the mammalian cerebral cortex. These classes include the pyramidal neurons, which comprise the principal source of efferent cortical axons (Lund et al., 1975; Katz, 1987; Buhl and Singer, 1989; Hübener et al., 1990; Einstein and Fitzpatrick, 1991 ) and a population of nonpyramidal cells with spiny dendrites, the spiny stellate cells (Lund, 1984). Both give rise to extensive intrinsic axonal projections. The interlaminar and horizontal connections formed by axon collaterals of pyramidal cells provide an elaborate plexus of synaptic contacts to other cortical neurons (Gilbert and Wiesel, 1979, 1983; Martin and Whitteridge, 1984). Such connections arise from stereotyped patterns of axonal branches given off by pyramidal cells in cortical layers II, III, V, and VI (Feldman, 1984; Martin and Whitteridge, 1984). Together, these layer-specific patterns of axon collaterals form one essential component of a basic circuit that exists across different functional areas of cortex. The spiny stcllate cells are more restricted in their laminar distribution and in their axonal projection. Most of their somata occupy a narrow band that includes layer IV, where they receive a dense thalamocortical innervation (Lund, 1973, 1984). From those layers, some spiny stellate neurons send their axons into other areas of the cerebral cortex (Buhl and Singer, 1989; Einstein and Fitzpatrick, 1991), but the majority form exclusively intracortical connections with neurons in the superficial layers (Lund, 1973, 1984).

Several lines of evidence indicate that the pyramidal neurons synthesize and release an excitatory amino acid (glutamate or aspartate) as a neurotransmitter. The range of data, summarized by Streit (1984), includes reductions in the endogenous concentration, release and uptake of glutamate in several targets of pyramidal cells following ablation of the cerebral cortex (LundKarlsen and Fonnum, 1978; Fosse et al., 1984), the ability of excitatory amino acid antagonists to block the postsynaptic effects of cortical stimulation (Hagihara et al., 1988; Huettner and Baughman, 1988; Jones and Baughman, 1988; Shirokawa et al., 1989; Nishigori et al., 1990), and the retrograde transport of D-aspartate from the sites of pyramidal cell axon terminations (Streit, 1980; Baughman and Gilbert, 1981; Matute and Streit, 
1985; Barbaresi et al., 1987; Kisvarday et al., 1989; Johnson and Burkhalter, 1992). A substantial body of recent research, particularly in the pharmacology of cortical synapses (for reviews, see Watkins and Olverman, 1987; Tsumoto, 1990), has reinforced the conclusion that many cortical pyramidal cells employ glutamate as a neurotransmitter. By contrast, little is known of the neurotransmitter(s) synthesized and released by the spiny stellate cells. Unlike the aspiny nonpyramidal neurons of the cerebral cortex, the spiny stellate cells do not display GABAergic traits: they do not exhibit immunoreactivity for GABA or for its synthesizing enzyme, glutamate decarboxylase (GAD) (Hendrickson et al., 1981; Houser et al., 1984; Gabbott and Somogyi, 1986; Fitzpatrick et al., 1987; Hendry et al., 1987). These findings, that spiny stellate cells do not contain the inhibitory amino acid GABA, are in agrecment with anatomical studies (LeVay, 1973; Saint-Marie and Peters, 1985) that indicate spiny stellate cells are excitatory interneurons.

One strategy for localizing all glutamate neurons in the cerebral cortex employs immunocytochemical staining for the amino acid itself (Storm-Mathisen et al., 1983) or for phosphateactivated glutaminase (PAG), an enzyme involved in its synthesis. In several areas of the mammalian cortex, a large proportion of neurons display an intense immunoreactivity for glutamate (Ottersen and Storm-Mathisen, 1984, 1987; Conti et al., 1987, 1988a, 1989; Dori et al., 1989) or for PAG (Donoghue et al., 1985; Kaneko and Mizuno, 1988; Akiyama et al., 1990). Because the immunostaining reveals both the distribution of neurons and their morphology, it has been possible to conclude that pyramidal neurons in all layers are glutamate positive (Conti et al., 1987, 1988a, 1989; Dori et al., 1989) and that spiny stellate cells in some areas may also be glutamate immunoreactive (Conti et al., 1989). These data not only support the findings of other, biochemically and pharmacologically based studies of cortical glutamate neurons (e.g., Tsumoto, 1990), but also provide a comprehensive picture of the organization of putatively excitatory cells in many cortical areas.

In the present study we have examined the glutamate-immunoreactive neurons of the primary visual area 17 of the macaque cerebral cortex. Neurons in area 17 of monkeys are organized into a complex series of layers, with the somata of most pyramidal neurons occupying primarily the layers above (II and III) and below (V and VI) layer IV (Lund, 1973). Spiny stellate neurons are found in layer IVB and in layers IVA and IVC (Lund, 1973), the sublaminae that receive direct innervation from axons originating in the dorsal lateral geniculate nucleus (LGN) of the thalamus (Hubel and Wiesel, 1972; Hendrickson et al., 1978; Blasdel and Lund, 1983). Based principally on the potential intracortical relay of excitation, models of cortical function have correlated the laminar organization of somata, dendrites, and axons with the characteristic physiological properties of neurons across the layers in monkey area 17 (Hubel and Wiesel, 1977; Szentagothai, 1978; Martin, 1988). Recent studies of neurotransmitters, receptors, and related molecules have contributed to these models by accenting the contribution of inhibitory, GABAergic neurons to area 17 (Hendrickson et al., 1981; Shaw and Cynader, 1986; Fitzpatrick et al., 1987; Hendry et al., 1987, 1990; Rakic et al., 1988; Shaw et al., 1991). As a means of analyzing the contribution of excitatory populations to neuronal circuits in area 17, one part of the present study examined the glutamate-immunoreactive neurons in normal adult monkeys.

A second part of this study examined the change in glutamate immunoreactivity brought on by monocular deprivation in adulthood. Previous studies have shown that removal of inputs from one retina in the adult monkey reduces the level of immunoreactivity for $\mathrm{GABA}, \mathrm{GAD}$, and $\mathrm{GABA}_{\mathrm{A}}$ receptors in cortical neurons dominated by the deprived retina (Hendry and Jones, 1986, 1988; Hendry et al., 1990). At the same time that inhibitory markers are reduced by monocular deprivation, deprived-eye neurons of monkey area 17 display increased immunoreactivity for type II calmodulin-dependent protein kinase (CaM II kinase), an enzyme present in non-GABAergic, pyramidal and spiny stellate neurons of the monkey cerebral cortex (Hendry and Kennedy, 1986). Because of the central role played by excitatory neurons in normal intracortical circuits, an effect on their transmitter levels would be likely to influence the balance of excitation and inhibition in the cortex. Our aim, then, was to determine if glutamate levels are also regulated by synaptic activity and whether that regulation represented an increase or reduction in immunoreactive levels. Some of the results have been published in abstract form (Carder et al., 1991).

\section{Materials and Methods}

Seven adult monkeys (Macaca fascicularis and Macaca mulatta) were used in this study. Three of the animals were normal, and four received intraocular injections of tetrodotoxin (TTX; 10-15 $\mu \mathrm{g}$ in $10 \mu \mathrm{l}$ of normal saline) every fifth day for $5-25 \mathrm{~d}$ before death. Examination of direct and consensual light reflexes indicated that retinal activity remained suppressed throughout the $5 \mathrm{~d}$ period. All animals were killed with an overdose of Nembutal, followed by perfusion through the heart with 2$4 \%$ paraformaldehyde and $0-0.2 \%$ glutaraldehyde in $0.1 \mathrm{~m}$ phosphate buffer. The occipital lobes from each monkey were cut into sagittal blocks that included area 17 . Blocks were sunk in $20-30 \%$ sucrose/ phosphate buffer solution at $4^{\circ} \mathrm{C}$.

Most sections were cut serially on a sliding microtome. Some blocks of occipital cortex were cut sagittally. Others were flattened while freezing and were cut parallel to the opercular surface of the occipital lobe. Sections of varying thickness were cut and processed (alternating 15 and $30 \mu \mathrm{m}$ or 20 and $40 \mu \mathrm{m}$ ). The thicker sections in each series were reacted histochemically for cytochrome oxidase (CO) (Wong-Riley, 1979) or stained with thionin. Thinner sections were processed immunocytochemically for glutamate. Blocks from each of the normal monkeys were cut sagittally on a Vibratome at $100 \mu \mathrm{m}$. These sections were postfixed in osmium tetroxide, dehydrated, and embedded in Spurr's resin. Pieces from the sections were cut out and glued onto resin blanks. They were trimmed and recut at $1 \mu \mathrm{m}$, heat-mounted onto sialinized slides, etched with ethanolic sodium hydroxide, and processed for postembedding immunocytochemistry (de Jong et al., 1987).

The anti-glutamate antibodies were raised in rabbit or mouse against glutamate conjugated to keyhole limpet hemocyanin with glutaraldehyde. They were used at dilutions of 1:6000-1:12,000 (Hepler et al., 1988), 1:12,000 (Chemicon Inc., Temecula, CA), or 1:40,000 (Pel-Freez, Rogers, AK). Sections were preincubated in $0.05 \%$ Triton X-100 and 3-10\% normal serum in $0.1 \mathrm{M}$ phosphate buffer (dilution buffer). They were transferred to a solution containing glutamate antibody and incubated for $48-72 \mathrm{hr}$ at $4^{\circ} \mathrm{C}$ (frozen sections) or overnight at room temperature (semithin sections). Subsequently, the sections were processed by the avidin-biotin peroxidase method (Vector Labs, Burlingame, CA) and reacted in 3, $3^{\prime}$-diaminobenzidine tetrahydrochloride and hydrogen peroxidase. Some immunostained frozen sections were osmicated or counterstained with thionin. Specificity of the glutamate antibody was tested by preadsorbing the primary antibody with an excess of glutamate-BSA conjugate, which eliminated all specific immunoreactivity or GABA-BSA conjugate, which had no effect on the pattern of intensity of immunoreactivity. Sections in which the normal rabbit scrum $(1: 1000)$ was substitutcd for the primary antiscra also served as control.

For simultaneous immunofluorescent detection of glutamate and GABA, 5- or $10-\mu \mathrm{m}$-thick sections were preincubated in $10 \%$ normal horse serum before incubation in the two primary antibodies (mouse anti-glutamate, 1:40,000; rabbit anti-GABA, 1:10,000; Sigma, St. Louis, $\mathrm{MO})$ for $24 \mathrm{hr}$ at $4^{\circ} \mathrm{C}$. The sections were then washed and primary antibodies were localized with secondary antibodies conjugated to dif- 


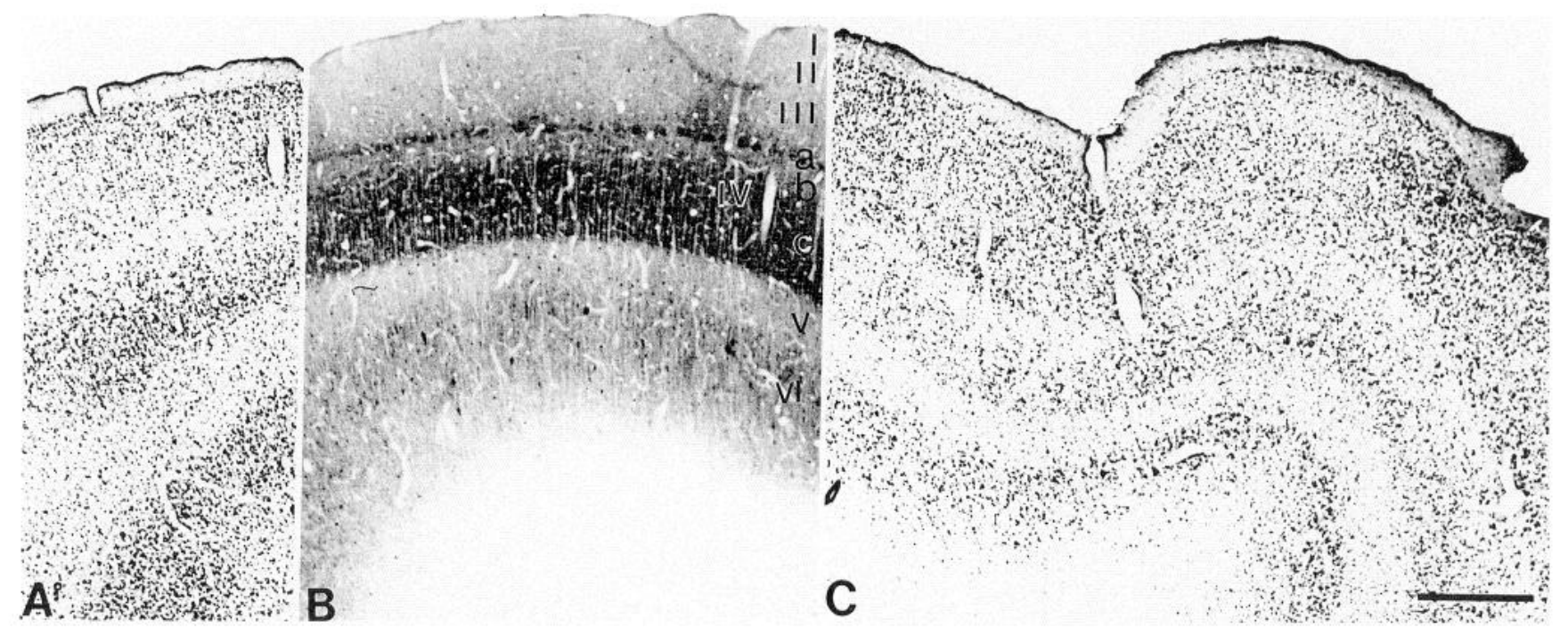

Figure 1. Laminar distribution of glutamate-immunoreactive neurons in monkey area 17. The distribution of immunostained neurons was determined by comparing an oblique section through area 17 immunostained for glutamate $(A$ and $C)$ with an adjacent section stained for CO $(B)$. The most intense immunostaining is present in two sublayers of layer IV (layers IVA and IVC) and in layers II-III and VI. Scale bar, $450 \mu \mathrm{m}$.

ferent fluorochromes (fluorescein isothiocyanate or Texas red). The sections were then washed and mounted on slides in phosphate-buffered glycerol (1:3) containing $10 \mathrm{~mm}$ purpurogallin, examined, and photographed with Nikon and Zeiss eipfluorescence microscopes equipped with FITC and rhodamine excitation filters.

Measurements of cross-sectional area were done on 15- $\mu$ m-thick immunostained sections with the aid of a Bioquant IV computer-assisted image analysis system (R \& M Biometrics, Inc.). Samples were taken from two normal monkeys, and only neurons with a nucleus in the section were measured. Mean, maximum, and minimum values were calculated for glutamate-immunoreactive somata in each layer.

\section{Results}

\section{Laminar distribution of glutamate immunostaining}

In area 17 of normal monkeys, glutamate immunostaining formed three bands containing large numbers of immunostained somata and three bands that contained fewer (Fig. $1 A, C$ ). When compared with the pattern of $\mathrm{CO}$ in adjacent sections (Fig. $1 B$ ) or in immunostained sections counterstained with thionin (Fig. 2), the dense bands were determined to be layers II-IVA, IVC, and VI and the sparse bands layers I, IVB, and V. A thin sublamina of closely packed, intensely immunoreactive neurons marked the junction between layers I and II.

Glutamate-immunoreactive somata included two major morphological types (Figs. 3-6). The majority were triangular or teardrop shaped; each gave rise to a single large dendrite from its apex and several dendrites from its base (Figs. $3 A-C, 5 C$ ). Immunostained branches from these dendrites were rarely observed. The second type of soma was round and gave rise to no immunostained processes (Figs. $3 A, B ; 4 A, B ; 5 B$ ). These two cell types accounted for the majority of somata in monkey area 17 , as judged from counterstained preparations by the higher density of immunostained neurons than those stained only for thionin (Fig. 2). However, thionin-stained nonimmunoreactive neuronal somata were present in every layer and made up the majority of somata in layer I (Fig. 2A).

The size of immunostained pyramidal cells varied with depth in the cortex, as somata present in layer II were smaller (mean area $=64 \mu \mathrm{m}$ ) than those present in the deep layers (layer $\mathrm{V}$ mean area $=116 \mu \mathrm{m})$. A unique class of pyramidal neurons found in the upper half of layer VI was exceptionally large and had a mean cross-sectional area of $438 \mu \mathrm{m}$ (Fig. $5 C$ ). These were the same size as deep Meynert cells (e.g., Fries et al., 1985).

Simultaneous immunofluorescent detection of glutamate and GABA revealed two distinct and nonoverlapping populations of neurons in all layers of monkey area 17 (Fig. 6). Both in those layers (II-III and V-VI) where the triangular somata with immunostained primary dendrites predominated (Fig. $6 A-D$ ), and in layers IVA and IVC (Fig. $6 E, F$ ), where the round somata with no immunostained processes were densest, no glutamateimmunoreactive somata were immunoreactive for GABA, and no GABA-immunoreactive neurons were immunoreactive for glutamate.

In addition to immunostained somata, other neuronal elements contributed to the pattern of glutamate immunoreactivity. Within the white matter were many large, immunostained processes that extended obliquely or horizontally, frequently for more than $1 \mathrm{~mm}$ (Fig. $5 D$ ). These processes were surrounded by narrow pale regions, giving them the appearance of immunostained axons surrounded by myelin sheaths (Figs. $3 D, 5 A, D$ ). Radially oriented immunostained processes could be traced from the white matter through layers VI and V and into layer IVC (Fig. $5 A$ ), where they gave rise to finer processes (Fig. $4 A, B$ ). Other immunostained neuronal elements in the cortex included small punctate profiles and a fine lattice of immunostained processes in the neuropil (Fig. 3C,D). The fine processes were apparent with bright-field illumination and were particularly evident both under dark-field (Fig. $4 C$ ) and in semithin sections (Fig. $3 C, D$ ), where their position in the neuropil suggests they are small-diameter axons.

\section{Intralaminar patterns of glutamate immunostaining}

In tangential sections through layers II and III, intense glutamate immunostaining was distributed in periodic patches (Figs. 7, 8). Comparison of adjacent sections stained immunocytochemically for glutamate (Fig. $7 A$ ) and histochemically for $\mathrm{CO}$ (Fig. 


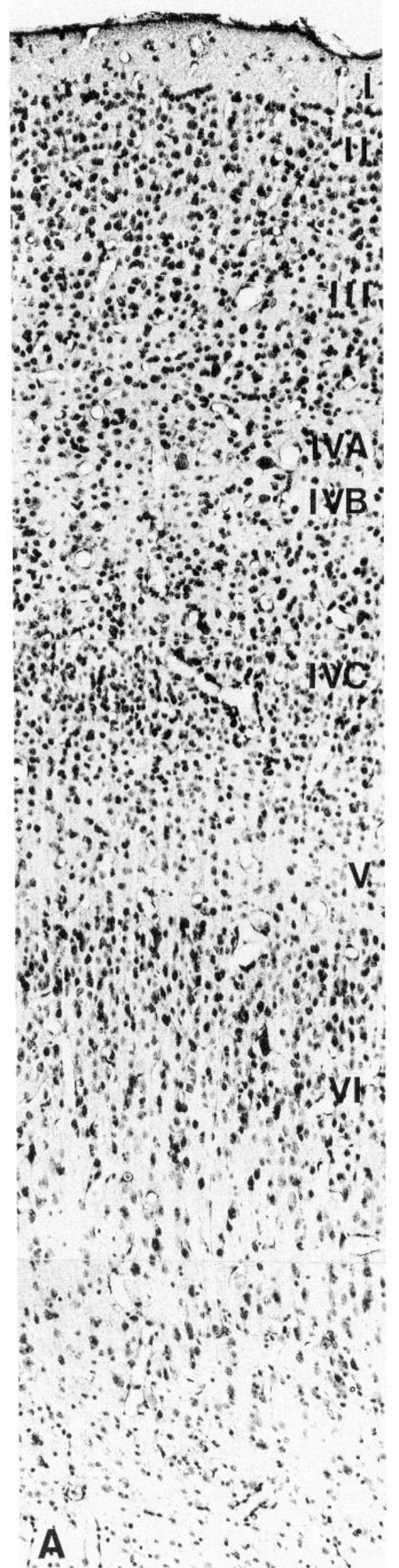

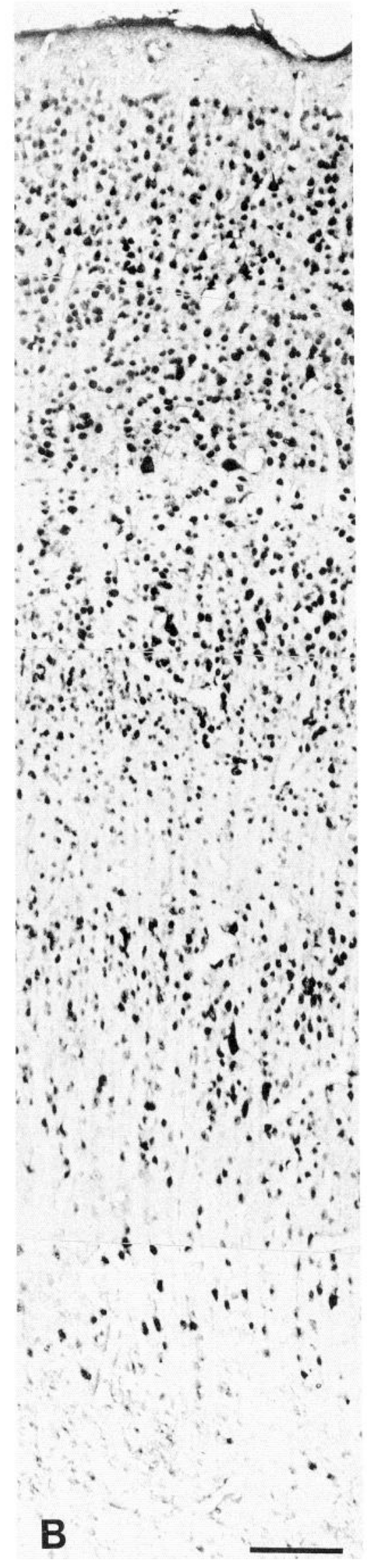

Figure 2. Distribution and density of glutamate-immunoreactive neurons in monkey area 17: photomicrographs of a section immunocytochemically stained for glutamate only $(B)$ and of the same section after it was counterstained with thionin $(A)$. The density of glutamate neurons follows closely the density of all neurons in this area. Comparison of immunostained and thionincounterstained micrographs reveals the presence of many neuronal somata that do not exhibit glutamate immunoreactivity. Scale bar, $100 \mu \mathrm{m}$. 

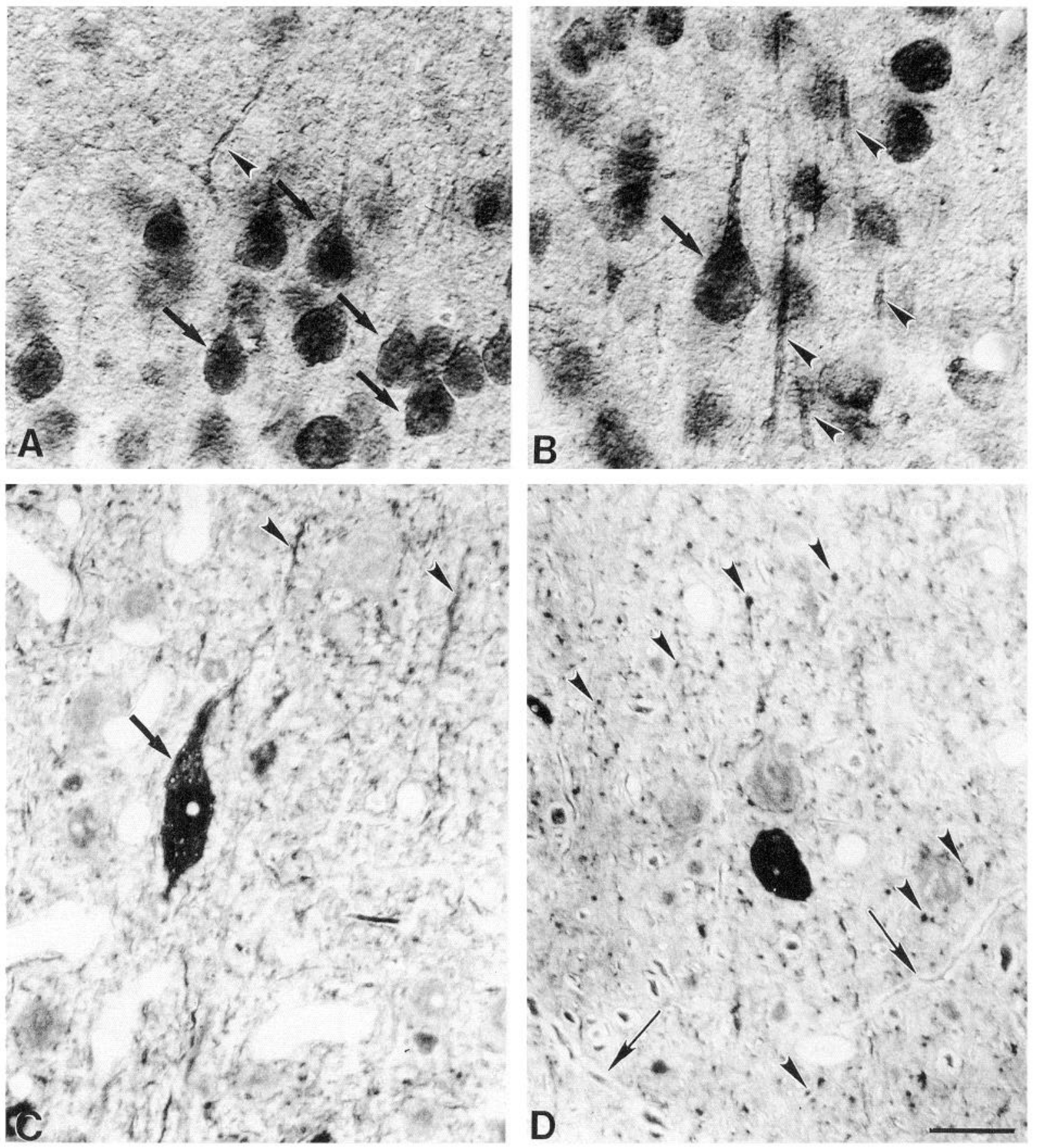

Figure 3. Glutamate-immunoreactive elements in layers II and III of monkey visual cortex. A, The densely packed glutamate-immunoreactive neurons in layer II have pyramidal somata (arrows) and give rise to prominent ascending dendrites, some of which branch in layer I (arrowhead). $B$, Immunostained neurons in layer III include many with large somata (arrow). Numerous radially oriented dendrites (arrowheads) are also present in this layer. $C$, Pyramidal somata (arrow) and radially oriented processes (arrowheads) are also evident in semithin sections through layer III. Numerous fine processes and punctate profiles are present in the neuropil. $D$, Deep layer III contains a high density of punctate profiles, some of which are indicated by arrowheads. Also present in this layer are thin immunostained processes surrounded by unstained regions (arrows), which appear to be immunostained myelinated axons. Scale bar, $25 \mu \mathrm{m}$.

$7 B$ ) demonstrated that many glutamate-positive patches coincided with puffs of intense CO staining. Both measured $150 \times$ $250 \mu \mathrm{m}$ with a center-to-center spacing of 400-600 $\mu \mathrm{m}$ (Fig. 7). These patches contained somata that were more intensely immunostained than the cells in the surrounding interpatch regions (Fig. $8 \mathrm{~A}$ ). In addition, many immunostained processes occupied the neuropil in the patches. Particularly evident in dark-field illumination was the discrete nature of this immunostaining in the neuropil (Fig. 7A).

In layer IVA, glutamate immunostaining formed clusters or islands of intense immunoreactivity measuring $70-100 \mu \mathrm{m}$ in diameter (Figs. $8 A, 9 A-C$ ). With dark-field illumination, these islands were seen as irregular, bright regions surrounded by a thin lattice of very weak immunostaining. The CO staining re- 

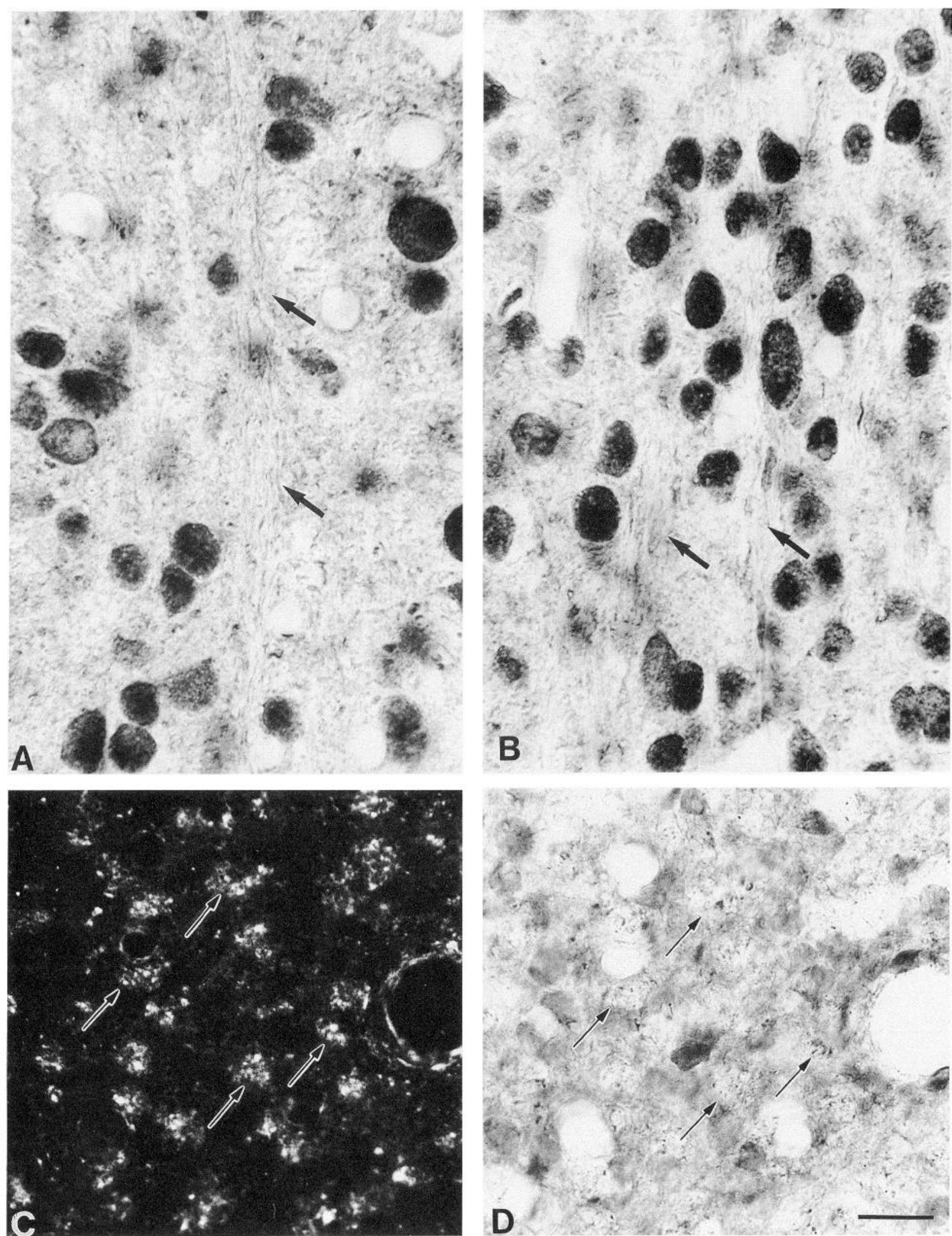

Figure 4. Glutamate-immunoreactive elements in layers IVB and IVC. $A$, In layer IVB, glutamate-immunostained somata differ in size but most are round. Bundles of radially oriented processes (arrows) are commonly observed in this layer. $B$, Small, densely packed neurons, most with round somata, dominate the glutamate immunostaining of layer IVC. Interspersed among the somata are bundles of radially oriented processes (arrows). In both layers IVB and IVC, numerous punctate profiles in the neuropil are also immunostained. $C$ and $D$, Dark-field $(C)$ and bright-field $(D)$ photomicrographs of the same region in a tangential section through layer IVC. The immunostaining in dark field appears as clusters of bright immunoreactivity (arrows), which correspond in bright field to regions containing thin immunostained processes and large punctate profiles. Scale bar: $15 \mu \mathrm{m}$ for $A$ and $B, 25 \mu \mathrm{m}$ for $C$ and $D$. 

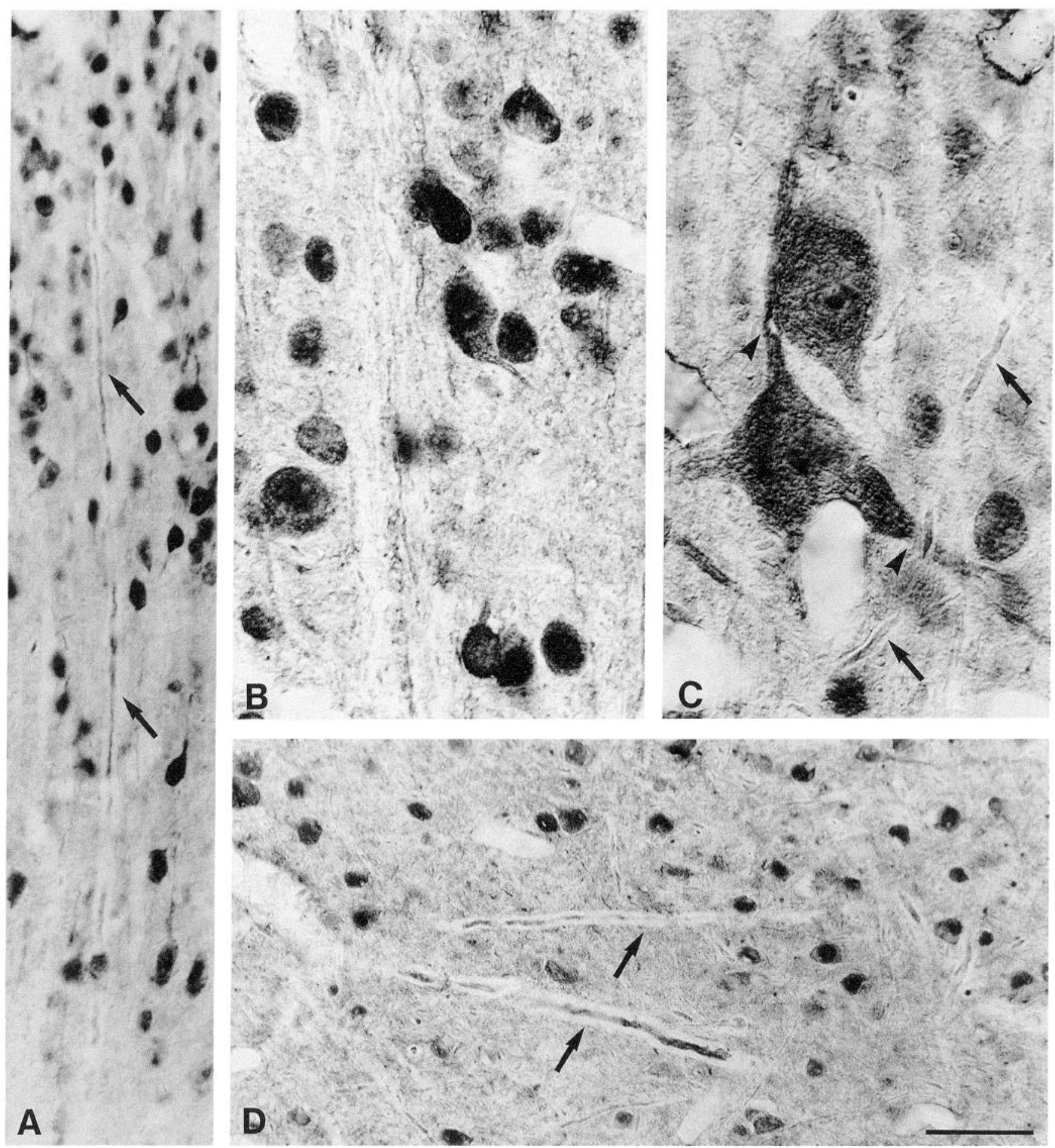

Figure 5. Glutamate-immunoreactive neurons in layers V and VI. Two types of elements are intensely immunostained in these layers. One includes large-diameter processes (arrows in $A, C$, and $D$ ), many of which are radially oriented and extend for more than $1 \mathrm{~mm}(A)$. Others are obliquely $(C)$ or horizontally oriented $(D)$. In most cases, these processes are flanked by narrow unstained regions $(A$ and $D)$, which gives them the appearance of immunostained axons surrounded by unstained myelin sheaths. Numerous somata are also immunostained, which vary greatly in size and include extremely large somata in layer VI $(C)$, presumed to be deep Meynert cells. The large layer VI somata give rise to numerous immunostained processes (arrowheads in $C$ ). Scale bar: $50 \mu \mathrm{m}$ for $A, 20 \mu \mathrm{m}$ for $B-D$.

vealed the reverse pattern, in which an intensely stained lattice surrounded weakly stained lacunae (Figs. $8 B, 9 D$ ). These patterns suggested that glutamate immunostaining and $\mathrm{CO}$ staining in layer IVA were complementary. Direct comparison of adjacent glutamate-immunostained (Fig. $9 \mathrm{C}$ ) and CO-stained (Fig.
$9 D$ ) sections through layer IVA confirmed that the CO-stained walls surrounded the glutamate-immunostained islands. In some cases, a single glutamate-positive island crossed a CO-rich lattice to fill two lacunae.

Immunostaining within the glutamate-rich islands was made 

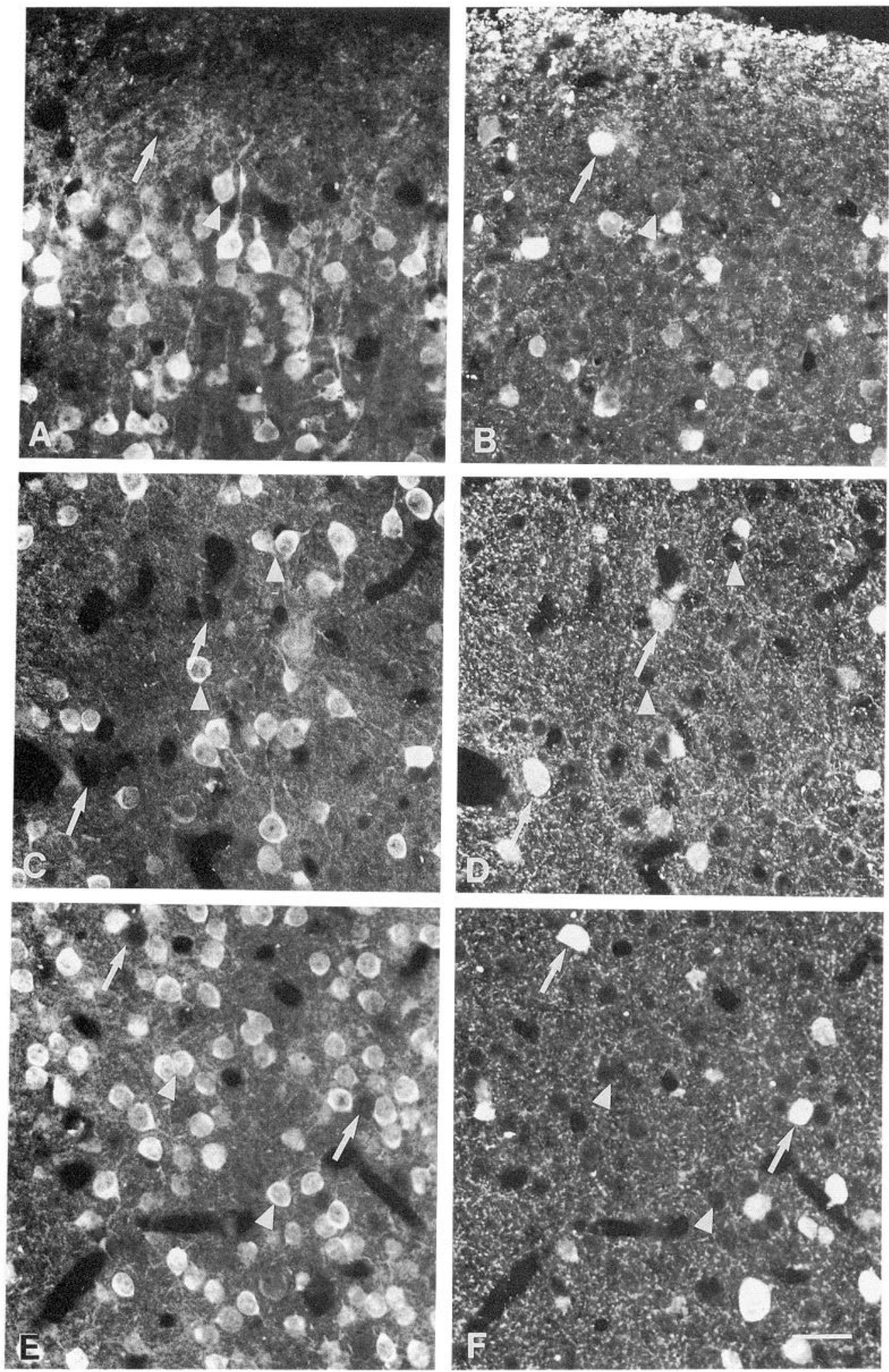

Figure 6. Neurochemical characterization of glutamate-immunoreactive neurons in monkey visual cortex: pairs of fluorescence photomicrographs comparing glutamate $(A, C$, and $E$ ) with GABA $(B, D$, and $F)$ immunostaining in the same sections through layers II $(A$ and $B)$, III ( $C$ and $D)$, and IVC ( $E$ and $F$ ). A simultaneous immunofluorescence method allowed GABA neurons to be viewed with a rhodamine filter and glutamate with a fluorescein filter. Although many neurons in each layer are immunoreactive for glutamate and GABA, none is immunostained for both. Examples of neurons that are immunostained for glutamate but not GABA (arrowheads) or GABA but not glutamate (arrows) are indicated. Scale bar, $25 \mu \mathrm{m}$.

up of several elements. These included intensely immunostained processes, which varied from thin fibers to bulbous expansions, and clusters of lightly immunoreactive somata (Fig. 10A,B). The weakly immunostained lattice that surrounded the islands contained lightly immunoreactive processes and few immunostained somata (Fig. 10).

The glutamate-immunoreactive neuropil in layer IVC was inhomogeneously distributed, as focal regions of intense immunoreactivity were interspersed among regions of less intense immunostaining (Figs. $4 C, D ; 11 B, C$ ). In tangential sections through layer IVC, the intensely immunostained regions measured 10-20 $\mu \mathrm{m}$ in diameter, while the lightly immunostained regions were larger. Comparison of the immunostaining in this layer with the $\mathrm{CO}$ staining showed that the glutamate pattern 

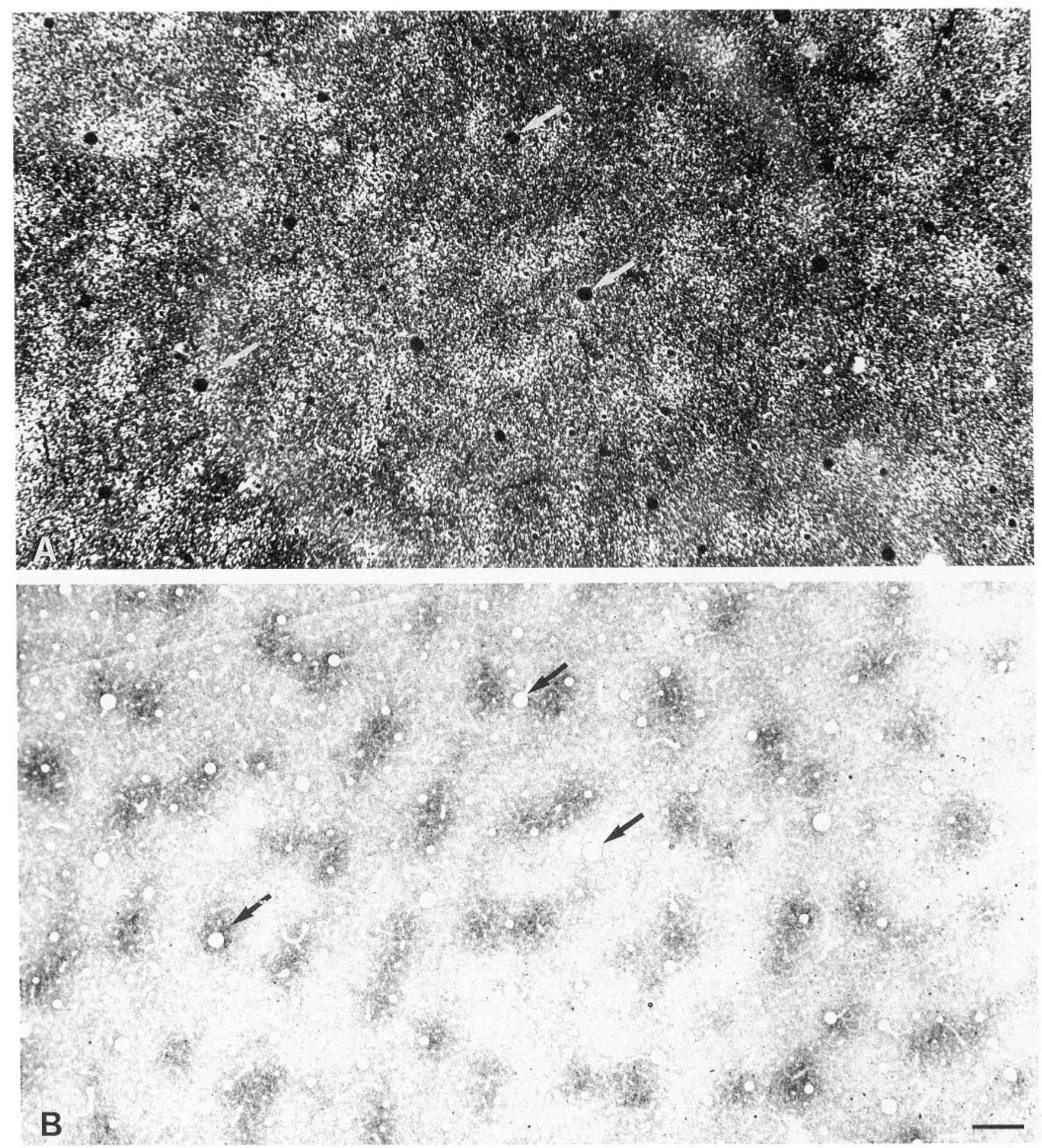

Figure 7. Comparison of glutamate immunostaining and $\mathrm{CO}$ staining in layers II and III. In a dark-field photomicrograph of a glutamateimmunostained section $(A)$ cut parallel to the lateral surface of the occipital lobe, numerous patches of intense neuropil immunostaining show up as bright regions. In an adjacent CO-stained section $(B)$, the puffs of intense histochemical reactivity are apparent. Comparison of the same blood vessel profiles in the two sections (arrows) demonstrates that the regions of the immunostained patches coincide with the regions of the CO-stained puffs. Scale bar, $250 \mu \mathrm{m}$.

and the $\mathrm{CO}$ pattern were complementary, with the glutamaterich regions coinciding with the $\mathrm{CO}$-poor zones (compare Fig. $11 A, B)$. Included within these regions of intensely immunostained neuropil were fibers, many of which were obliquely oriented, and punctate profiles (Figs. $4 D, 11 C$ ). Immunostained somata were, by contrast, evenly distributed and equally immunoreactive across layer IVC.

\section{Plasticity of glutamate in area 17}

After 5-25 d of monocular deprivation produced by injections of TTX into one eye of adult monkeys, the pattern of glutamate immunostaining changed in layer IVC (Fig. 12). In tangential sections through layer IVC of normal monkeys, glutamate immunoreactivity is rather homogeneous, with no evidence of 

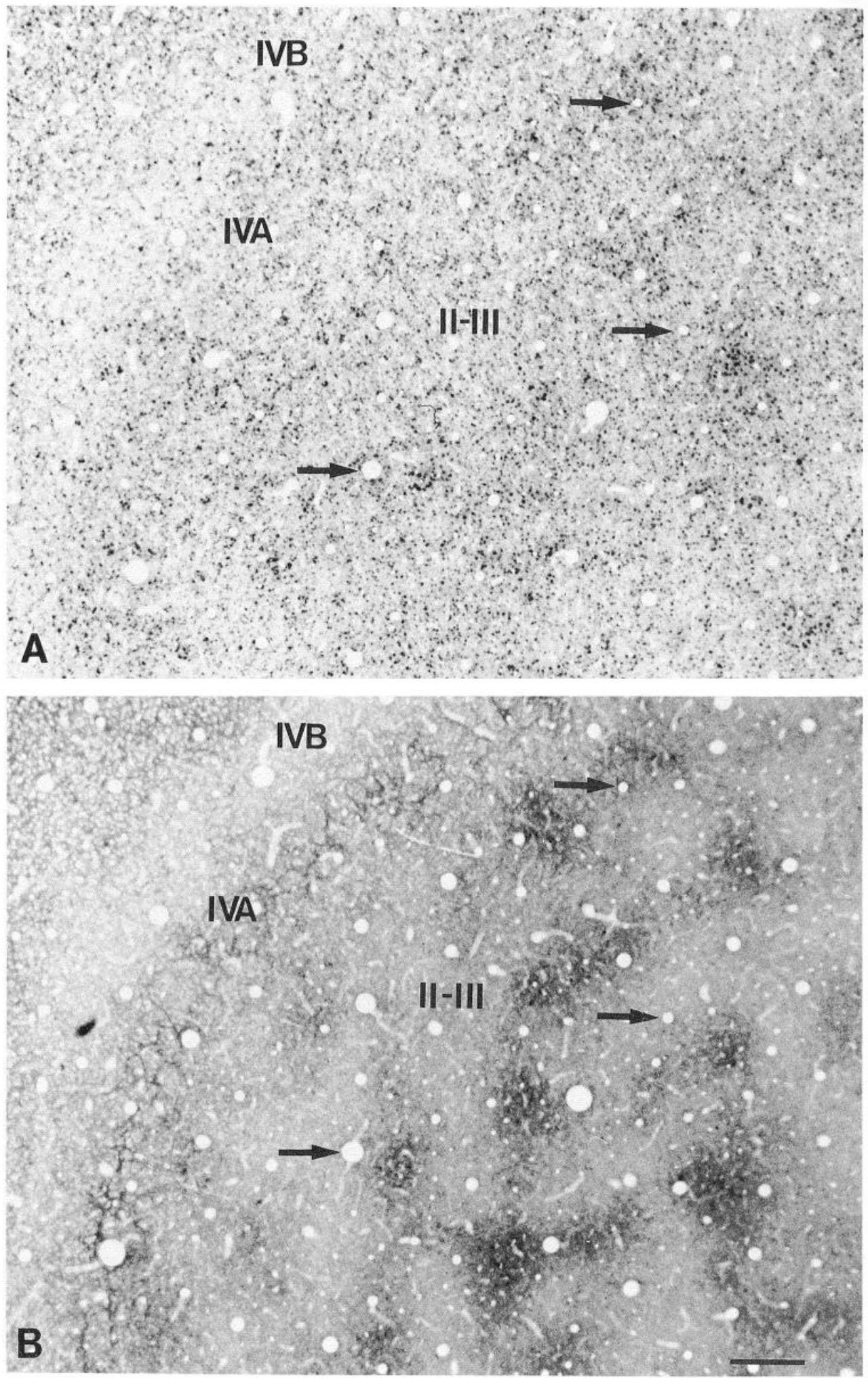

Figure 8. Comparison of glutamate immunoreactivity $(A)$ and CO staining $(B)$ in adjacent tangential sections through layers II-IVB. Evident in layers II-III and IVA in both sections is an uneven distribution of staining. $A$, Patches of immunostaining are present in layers II and III. These patches are made up of intensely immunostained somata and a generally more immunoreactive neuropil. In layer IVA, the intensely immunostained somata form small isolated clusters. $B$, CO staining reveals periodic puffs of intense histochemical activity in layers II and III and the lattice or honeycomb in layer IVA. Layer IVB displays light CO staining. Comparison of the positions of the same blood vessel profiles (arrows) indicates that the CO puffs in layers II and III coincide with the immunostained patches. The relationship of immunostained and $\mathrm{CO}$-stained elements in layer IVA is not clear at this magnification, but the clusters of glutamatepositive somata and the lightly $\mathrm{CO}$ stained lacunae are approximately the same size. Scale bar, $250 \mu \mathrm{m}$. regular, repeating shifts in immunostaining (Fig. 12A). However, glutamate immunoreactivity in tangential sections through layer IVC of a TTX-injected monkey consisted of alternating weakly and intensely immunostained stripes (Fig. 12B,C). Under bright-field illumination, in which somata and neuropil elements contributed to the relative intensity of immunoreactivity, the weakly and intensely stained stripes were equally wide, with each approximately $440 \mu \mathrm{m}$ in diameter (Fig. 12B). By contrast, in sections examined under dark-field illumination, which reveals the density of immunostained profiles in the neuropil but not immunostained somata, the stripes were of unequal widths: those weakly immunostained averaged $350 \mu \mathrm{m}$ in width, and those intensely immunostained, $520 \mu \mathrm{m}$ (Fig. 12C).

When compared with adjacent sections stained for CO (com- 

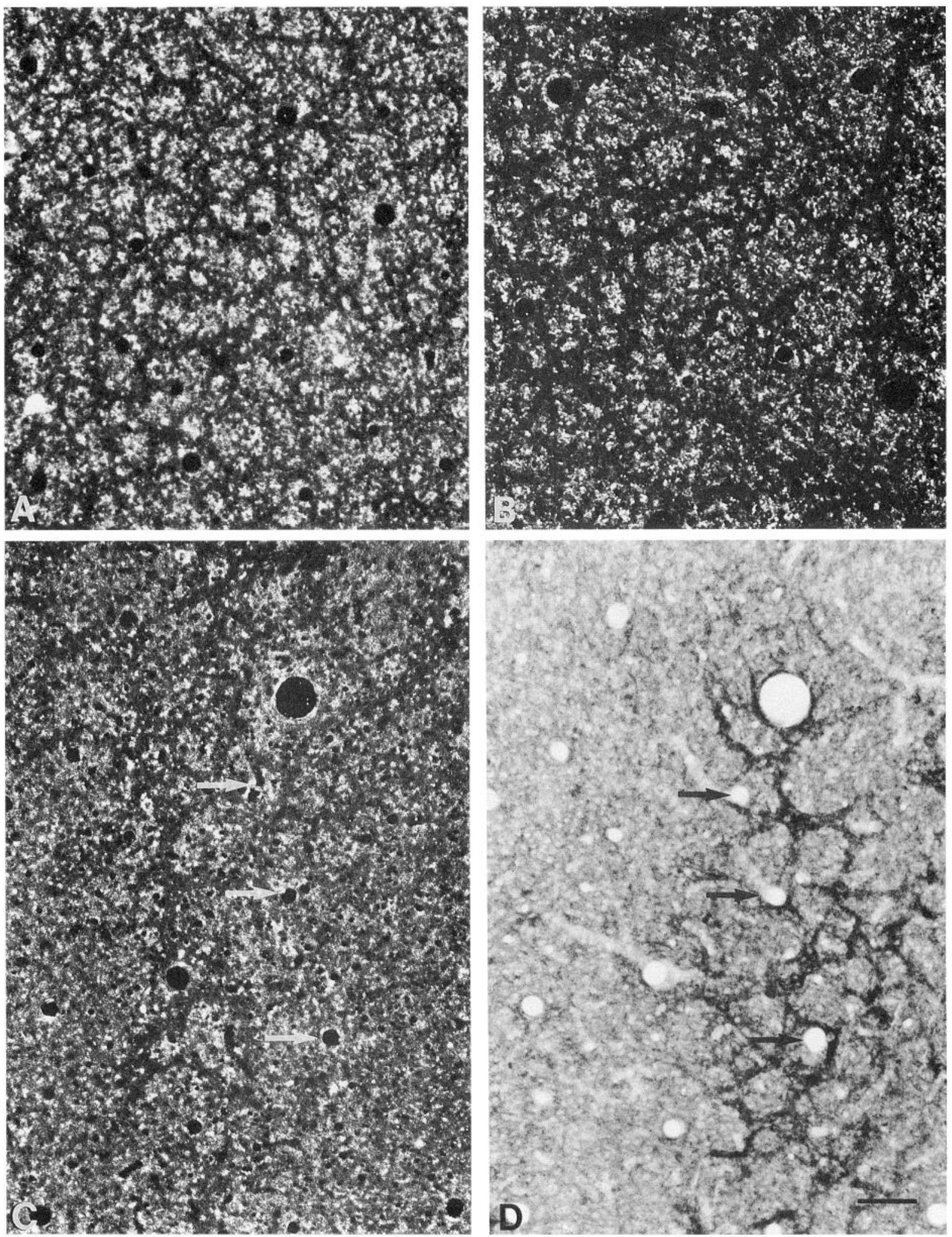

Figure 9. Clustered glutamate immunostaining in layer IVA. $A$ and $B$, Dark-field photomicrographs of tangential sections cut through layer IVA. The intense neuropil immunostaining, which appears as bright regions in these micrographs, is unevenly distributed in small clusters surrounded by a latticework of weak immunostaining (dark regions). The sizes of the clusters vary from 40 to $120 \mu$ m in major diameter. $C$ and $D$, Dark-field photomicrograph of glutamate immunostaining $(C)$ and bright-field photomicrograph of $C O$ staining $(D)$ in adjacent sections. The immunostaining of layer IVA is in the form of intense clusters surrounded by a weakly stained lattice, while the CO staining is of an intensely stained lattice that surrounds a series of weakly stained regions. Even though the position of the narrow layer IVA shifts slightly between the two sections, comparison of the same blood vessel profiles (arrows) demonstrates that the intensely immunostained regions correspond to the weakly CO-stained regions. Scale bar: $140 \mu \mathrm{m}$ for $A, 100 \mu \mathrm{m}$ for $B-D$. 

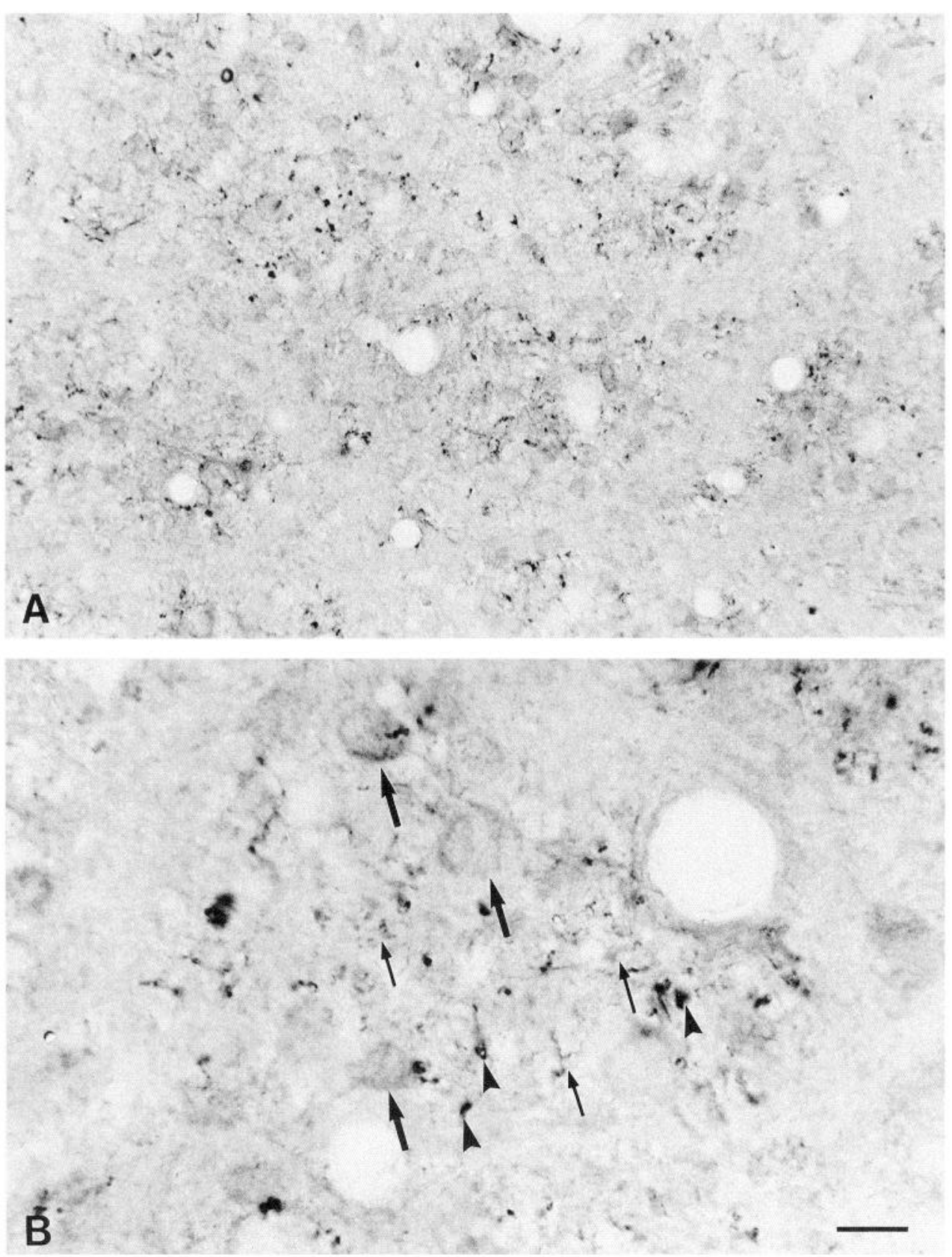

Figure 10. Glutamate-immunoreactive elements in layer IVA clusters. $A$, Photomicrograph of an immunostained section through layer IVA, cut parallel to the lateral surface of the occipital lobe. Clusters of intense immunostaining, made up of lightly immunoreactive somata, intensely immunoreactive large processes, and a moderately immunoreactive neuropil, occupy regions $40-120 \mu \mathrm{m}$ in diameter. The patches are separated from one another by lightly immunostained regions that contain very few immunoreactive somata or processes and a palely immunostained neuropil. $B$, High-magnification photomicrograph, showing the immunostained elements within an intensely immunoreactive cluster. In addition to numerous large processes (arrowheads), the patches contain immunostained somata (thick arrows) and a dense plexus of thin profiles (thin arrows) in the neuropil. Scale bar: 25 $\mu \mathrm{m}$ for $A, 10 \mu \mathrm{m}$ for $B$. pare Fig. $12 B, D$ ), the weakly immunostained stripes seen in bright field were found to coincide with the light $\mathrm{CO}$-stained stripes (deprived-eye columns) and intensely immunostained stripes with the dark CO-stained stripes (normal-eye columns). Comparison of dark-field images of immunostaining (Fig. 12C) with CO staining in adjacent sections (Fig. 12D) showed the weak immunostaining to occupy only the central two-thirds of the deprived-eye columns, while the intense immunostaining included all the normal-eye columns and peripheral parts of the adjacent deprived-eye columns. High-magnification photomicrographs (Fig. 13) showed that the reduced immunostaining in the deprived-eye columns was the result of an appreciably lower density of glutamate-immunoreactive somata than that present in normal-eye columns (Fig. 13A) and to a much-reduced level of neuropil immunostaining.
Changes in glutamate immunostaining were also evident outside of layer IVC. Such changes were robust in layers II and III of monocularly deprived adult monkeys, and were present but were less dramatic in layer IVA. In both dark-field (Fig. 14A) and bright-field (Fig. 15A) photomicrographs of layers II and III, intensely immunostained stripes measuring approximately $200-250 \mu \mathrm{m}$ in width were found to alternate with weakly stained stripes measuring 500-600 $\mu \mathrm{m}$ in width (Fig. 15A). Comparison of CO-stained (Figs. 14B, 15B) and glutamate-immunostained (Figs. 14A, 15A) sections in these layers revealed that the intensely immunostained stripes coincided with the regions of $\mathrm{CO}$ stained puffs. These puffs were often fused to form an elongated stripe at the center of the normal-eye column (Fig. 15B). The thicker, weakly stained glutamate stripes corresponded not only to the puff and interpuff regions of the deprived-eye columns 


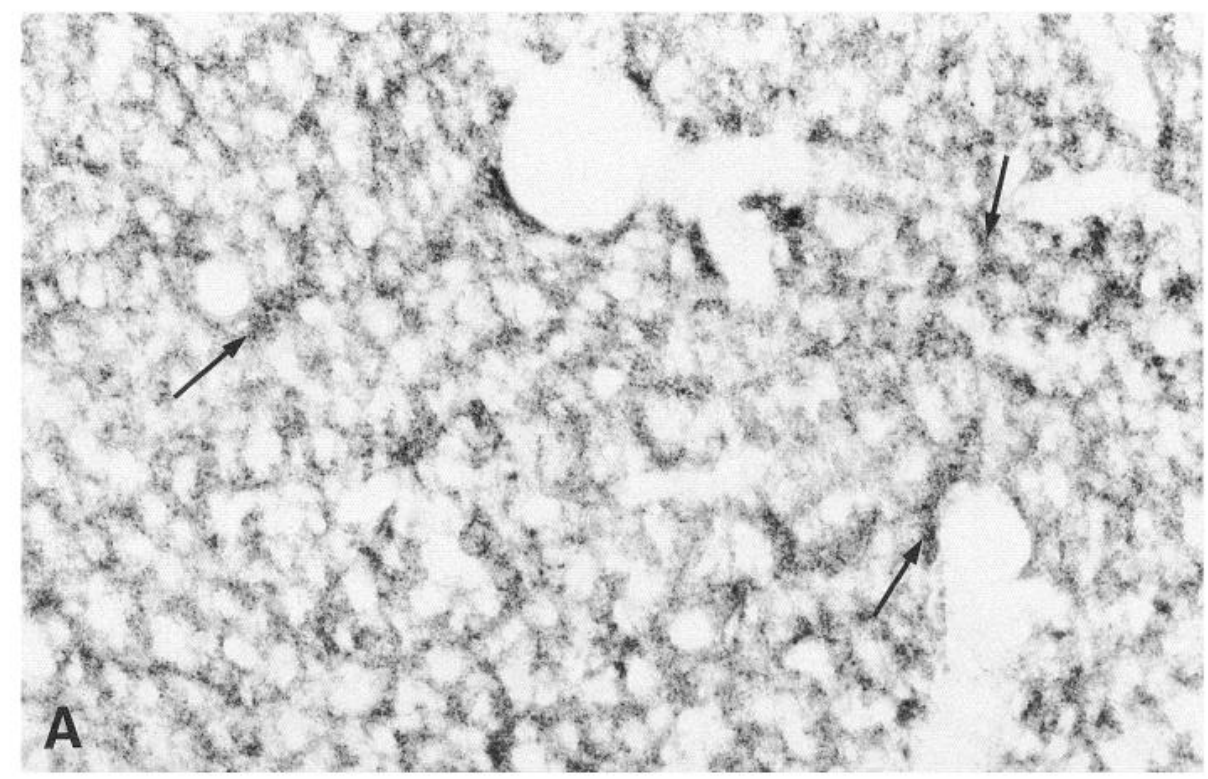

Figure 11. Glutamate immunostaining in layer IVC. $A$ and $B$, Comparison of $\mathrm{CO}$ staining and glutamate immunostaining in tangential sections. $A$, Bright-field photomicrograph of patchy $\mathrm{CO}$ staining in layer IVC. The dark patches (arrows) are small and are separated from one another by regions of lightly stained neuropil and small unstained regions that are interpreted to be unreactive neuronal somata. $B$, Darkfield photomicrograph of a section adjacent to the one in $A$, showing the same region immunostained for glutamate. Irregularly distributed patches of intense immunoreactivity are evident, which occupy regions that are weakly stained for CO (arrows). C, Bright-field photomicrograph, showing the same section as in $B$ at higher magnification to illustrate the type of elements that are present within patches of layer IVC (arrowheads indicate the same blood vessel profile in the two sections). The patches consist of large immunostained processes and small neuropil elements. Immunostained somata appear more evenly distributed. Scale bar: $25 \mu \mathrm{m}$ for $A$ and $B, 10 \mu \mathrm{m}$ for $C$.
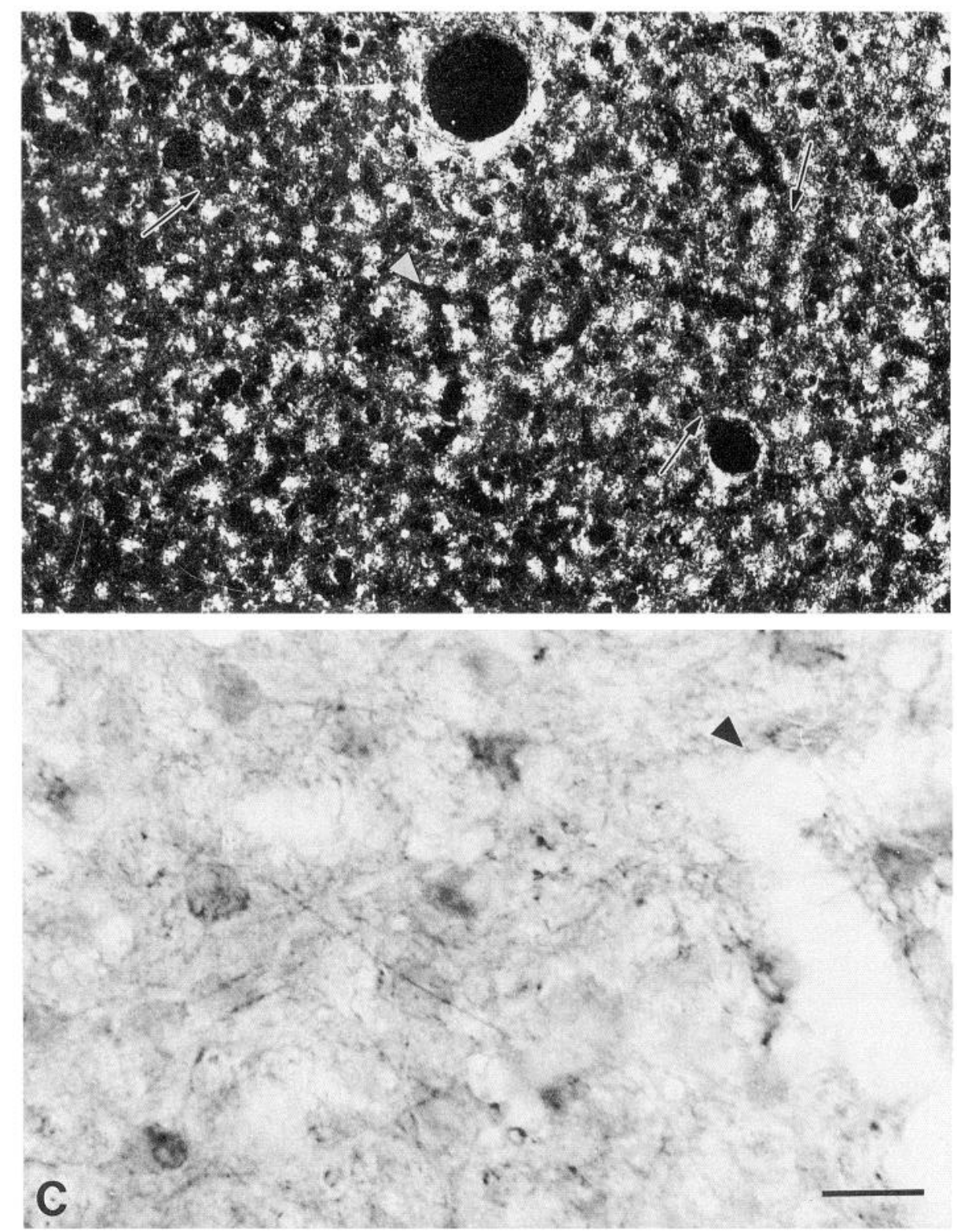

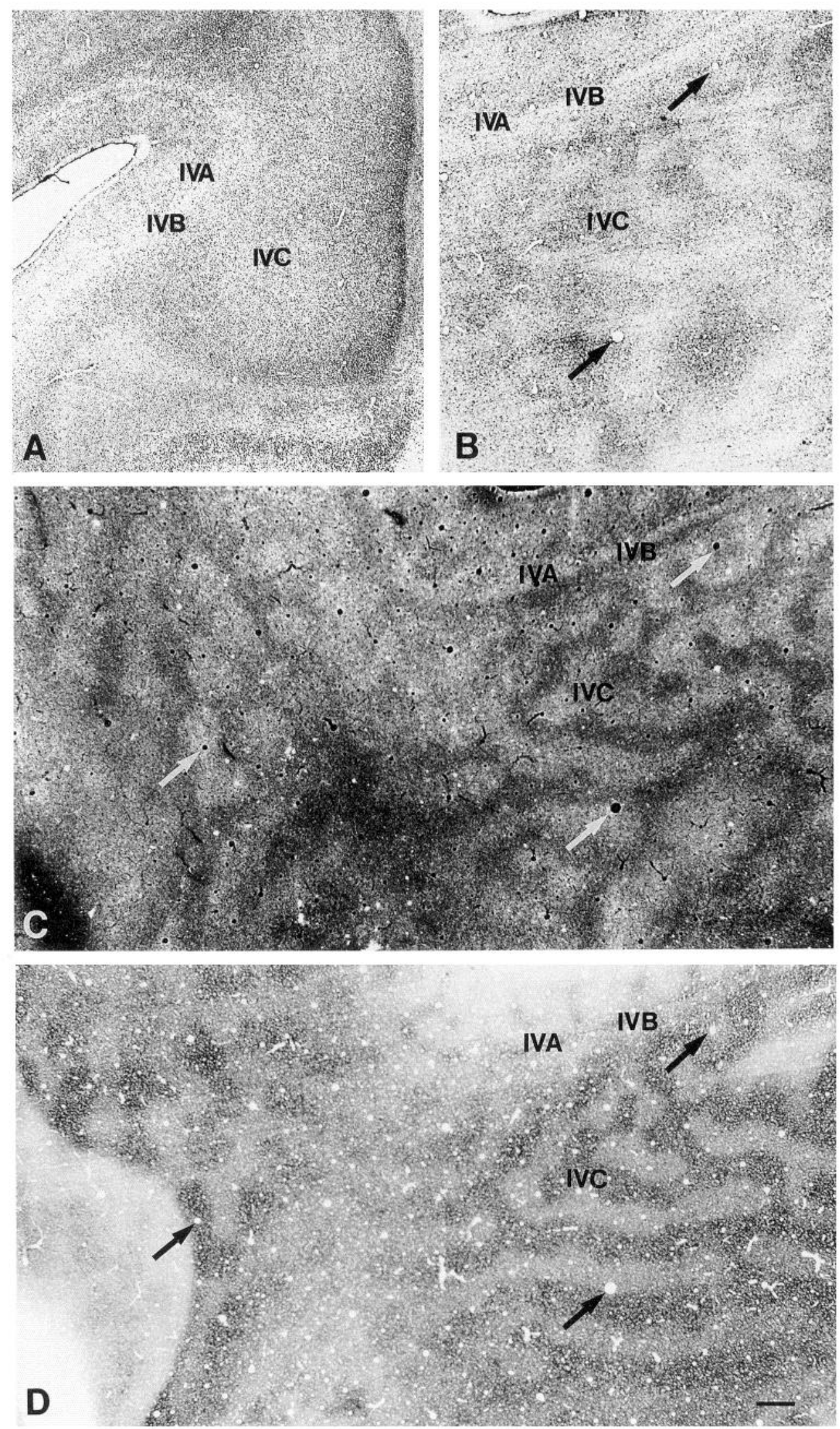

Figure 12. Regulation of glutamate immunostaining in layer IVC of adult monkeys. A, Low-power photomicrograph of glutamate immunostaining in a tangential section through layer IVC of a normal monkey. The distribution varies with depth, but no evidence of stripes can be detected. Following monocular deprivation for $20 \mathrm{~d}(B-D)$, glutamate immunostaining ( $B$ and $C$ ) and CO staining $(D)$ both consist of darkly and lightly stained stripes. Under brightfield illumination, both the lightly and darkly stained stripes are of equal widths, with the lightly stained stripes measuring approximately $440 \mu \mathrm{m}$. $C$, Dark-field photomicrograph showing the same section as in $B$. Darkly and lightly stained stripes are of unequal widths, with the lightly stained stripes measuring approximately $350 \mu \mathrm{m}$ in width and the darkly stained stripes 520 $\mu \mathrm{m}$. Comparison of the same blood vessel profiles (arrows) in the glutamateand $\mathrm{CO}$-stained sections shows the darkly stained glutamate and $\mathrm{CO}$ stripes coincide and the lightly stained glutamate and CO stripes coincide. Scale bar, $500 \mu \mathrm{m}$. 

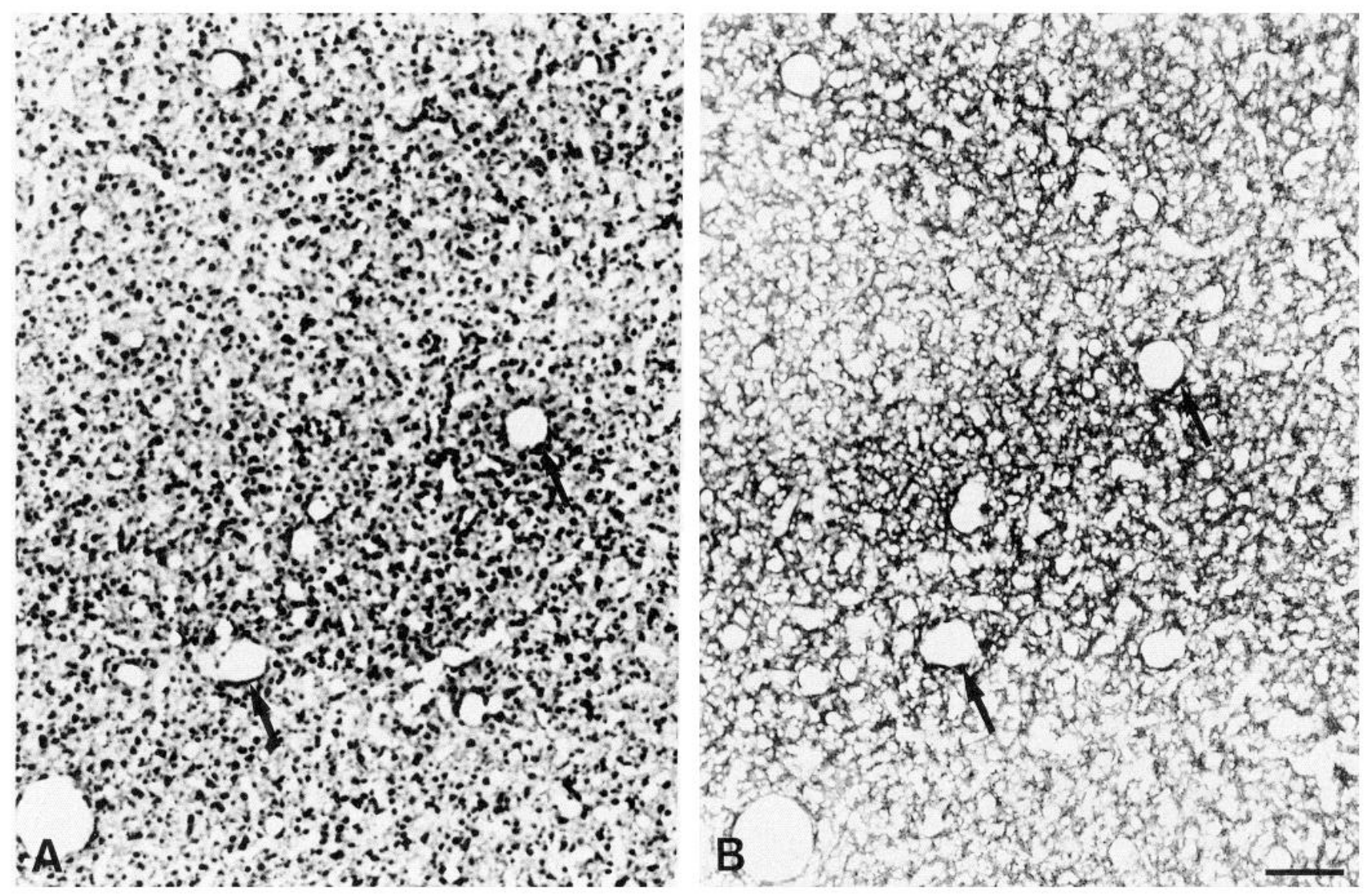

Figure 13. Reduction of glutamate immunostaining in ocular dominance stripes through layer IVC: higher-magnification photomicrographs of Figure $11, B$ and $D$, showing the glutamate immunostaining $(A)$ and $C O$ staining $(B)$ of alternating normal-eye and injected-eye columns. Comparison of the same blood vessel profiles in the two sections (arrows) reveals the dark glutamate stripes coincide with the dark CO stripes (normal-eye columns) and that the light glutamate stripes coincide with the light $\mathrm{CO}$ stripes (injected-eye columns). The number of immunostained neurons and neuronal elements and the intensity of their immunostaining in the injected-eye columns are greatly reduced from that in the neighboring normal-eye columns and from that in layer IVC of a normal monkey. Scale bar, $100 \mu \mathrm{m}$.

but also to the interpuff regions of the normal-eye columns. In layer IVA, the immunostained lattice also showed evidence of being divided into stripes or bands (Fig. 14A), with the more intensely stained regions corresponding to normal-eye columns, darkly stained for CO (Fig. 14B).

\section{Discussion}

Glutamate immunoreactivity exists within a distinct population of neurons in monkey area 17 , which is presumed to use this amino acid as a neurotransmitter. By employing glutamate immunoreactivity as a marker, one potentially specific for a large proportion of excitatory neurons in the visual cortex, we have focused on four principal findings: (1) both pyramidal cells and neurons likely to be spiny stellate cells are glutamate immunoreactive in monkey area 17 , while GABA neurons make up an entirely separate population; (2) glutamate-immunoreactive somata are densest in layers that receive geniculocortical terminations and tend to follow the normal packing density of all neuronal somata; (3) within geniculocortical-recipient layers of area 17, glutamate immunostaining is inhomogeneous, such that it is either coincident with (in layers II and III) or complementary to (in layer IVA) the pattern of geniculate terminations; (4) levels of glutamate immunoreactivity within cortical somata and processes undergo rapid changes following monocular deprivation in adulthood, in a manner that suggests that these levels are dependent on neuronal activity.

\section{Specificity of glutamate immunoreactivity}

Glutamate is an amino acid that operates at three well-recognized levels in neuronal function: (1) metabolic pools used in protein synthesis, (2) precursor pools used in the synthesis of GABA, and (3) neurotransmitter pools. Several lines of evidence suggest that glutamate immunoreactivity is composed principally of glutamate neurotransmitter. Quantitative immunocytochemical approaches in regions of well-characterized synaptology and physiology, such as the cerebellar cortex, find that much higher levels of glutamate immunoreactivity exist in excitatory neurons, for which substantial evidence indicates glutamate is a neurotransmitter (Somogyi et al., 1986; Ottersen et al., 1992). Our findings demonstrate that glutamate immunoreactivity in monkey area 17 is present selectively within neuronal populations (pyramidal and spiny stellate cells) that are considered to be excitatory and glutamate releasing on the basis of previous data. Clearly, glutamate immunostaining in this area does not uniformly follow patterns of metabolic activity. The mirror images of glutamate immunoreactivity and $\mathrm{CO}$ histochemical activity in the layer IVA honeycomb and in layer IVC 

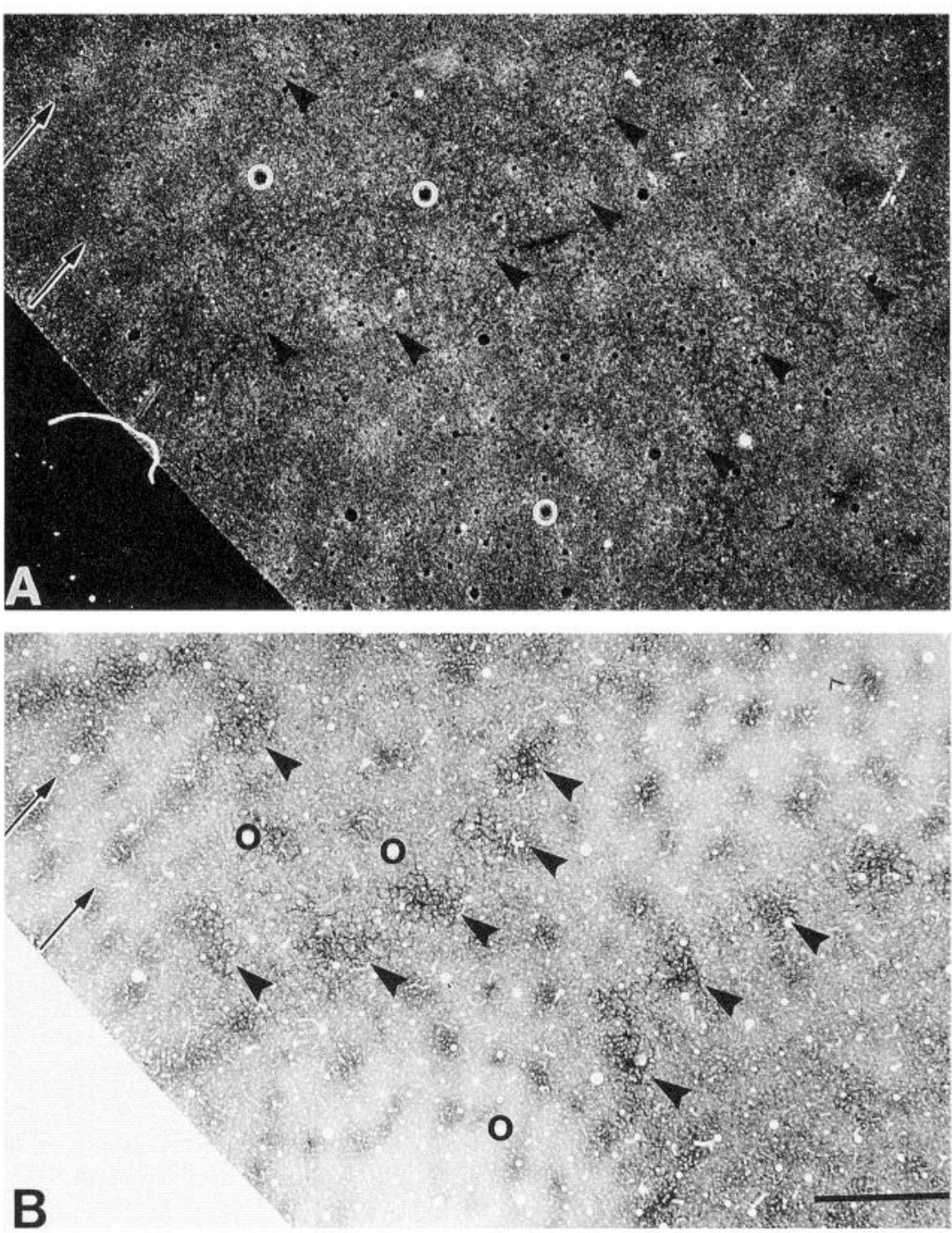

Figure 14. Glutamate immunoreactivity in layers II-III and IVA of a deprived monkey. Both the pattern of immunostaining, seen in dark field $(A)$, and of $\mathrm{CO}$ staining, seen in bright field $(B)$, consist of short stripes or bands in layer IVA (arrowheads). These bands alternate as intensely and weakly stained regions superimposed on the lattice in the CO-stained section and on the lacunae in the glutamate-immunostained section. Comparison of the same blood vessel profiles in the two sections (circles) shows that the intensely immunostained bands correspond with intensely CO-stained bands, indicating a reduction occurs in glutamate immunoreactivity and $\mathrm{CO}$ activity in regions of layer IVA dominated by the TTXinjected eye. In layers II and III, patches of intense glutamate immunostaining correspond to the regions of the $\mathrm{CO}$ rich puffs. Both glutamate and $\mathrm{CO}$ staining show an uneven pattern, with rows of intensely $\mathrm{CO}$-stained puffs and glutamate-immunostained patches ( $\mathrm{ar}$ rows) alternating with rows that are less intensely immunostained and $\mathrm{CO}$ stained. Scale bar, $1 \mathrm{~mm}$. demonstrate that on a regional basis, immunostaining and metabolic activity are not necessarily matched. Similarly, the failure to detect glutamate immunoreactivity in GABA neurons, which include some of the most metabolically active neurons in the cortex, indicates that at the level of single cells, metabolic activity does not lead to glutamate immunoreactivity. The lack of GABA/glutamate coexistence also indicates that pools of glutamate serving as GABA precursors were not localized by immunocytochemistry. Thus, the interpretation that is consistent with the available data is that immunocytochemical localization of glutamate by the methods used in this study recognizes preferentially and perhaps selectively the neurotransmitter pool of glutamate.

The extremely rich immunostaining of processes in the neuropil, evident in each of several dark-field (e.g., Figs. $4 C, 7 \mathrm{~A}$, $9 A-C, 11 B)$ and bright-field photomicrographs (e.g., Figs. 3-5), indicates that many small neuronal elements are glutamate immunoreactive. Thus, an important issue for interpreting the patterns of glutamate immunoreactivity, both in normal and monocularly deprived monkeys, is the identity of the immunostained neuropil elements. We intrepret them to be principally axons and axon terminals. This interpretation is based partly on the paucity of immunostained dendrites and the abundance of processes that closely resemble the large-diameter my- elinated axons that enter and terminate within monkey area 17 (e.g., Blasdel and Lund, 1983). Direct evidence of terminal labeling comes from analyses of frozen sections and semithin sections, immunostained with postembedding methods, which demonstrate that numerous punctate, terminal-like elements are immunostained throughout monkey area 17. Yet, the size of these punctate elements does not approach that of puncta immunostained for other neurotransmitters, including GABA (compare GABA and glutamate immunostaining in Fig. 6). That difference in size is most likely artifactual, arising from the localization of glutamate immunoreactivity to a fraction of the total cytoplasm in axon terminals of the mammalian cerebral cortex (Conti et al., 1989; Dori et al., 1989) and of other regions of the vertebrate nervous system (Farb et al., 1992; Shupliakov et al., 1992). Thus, the available data strongly suggest that axons and axon terminals make up a major component of glutamate immunostaining in the cerebral cortex. We conclude that the relative density and immunoreactivity of axons and terminals are major components in the immunostaining pattern of area 17 in normal and monocularly deprived adult monkeys.

\section{Excitatory neurons in monkey area 17}

Pyramidal cells are the most numerous of cortical neurons and are characterized by a morphology that includes a triangular 
Figure 15. Regulation of glutamate immunostaining in layers II-III of adult monkeys: photomicrograph of glutamate immunostaining $(A)$ and $\mathrm{CO}$ staining $(B)$ in adjacent tangential sections through layers II-III of a monocular-deprived monkey. Comparison of the same blood vessel profiles in the two sections (arrows) reveals the dark glutamate patches/stripes coincide with the dark $\mathrm{CO}$ puffs/stripes (normal-eye columns), while patches of intense glutamate immunostaining are no longer apparent within the shrunken puffs of the injected-eye columns. Scale bar, $250 \mu \mathrm{m}$.
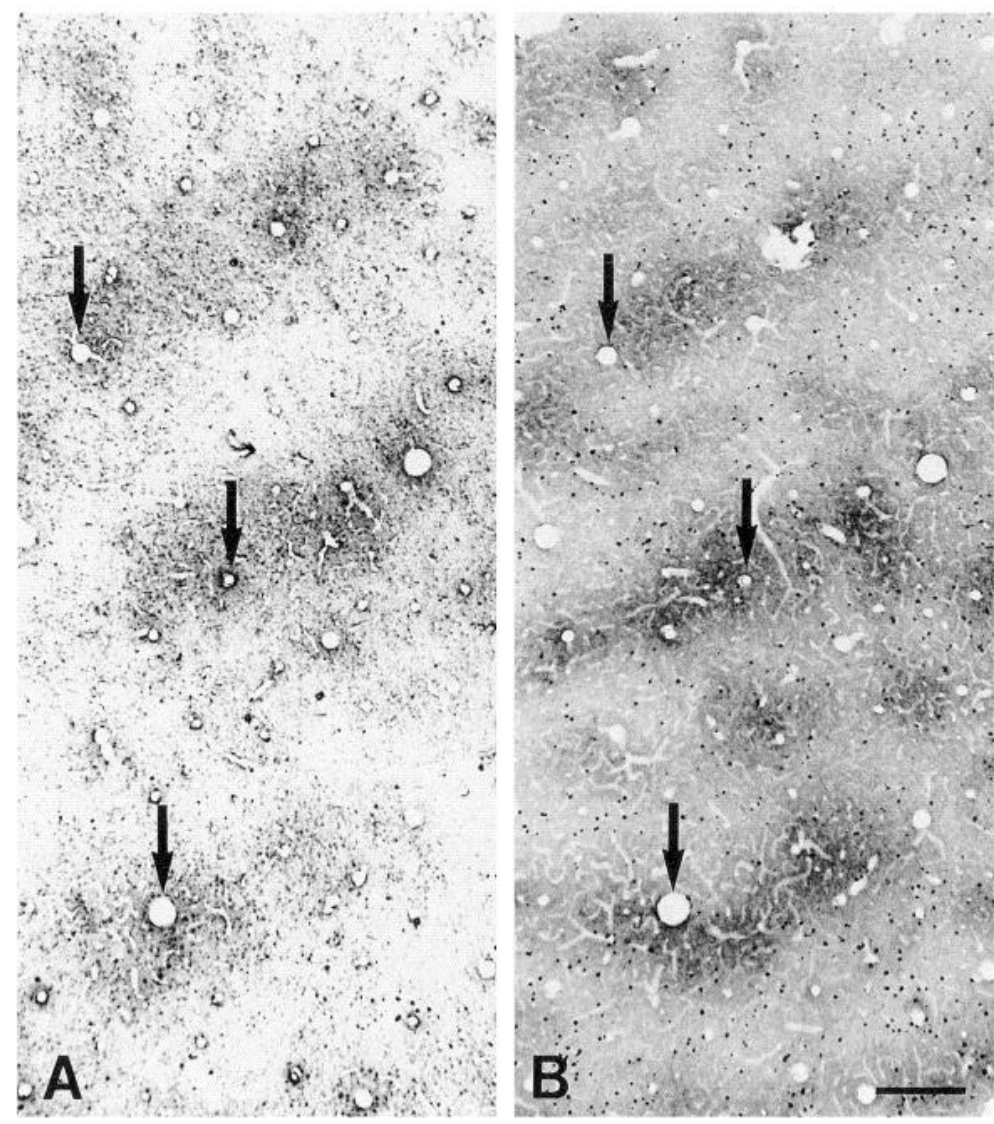

soma, prominent apical dendrite, basal dendritic system, and a descending axon (Feldman, 1984). Despite these common features, pyramidal cells are subdivided into groups based principally on the targets of their axons. These include several spatially segregated groups of pyramidal cells in layers II, III, and IVB that send their axons to the second visual cortical area (Livingstone and Hubel, 1984, 1987) and to other cortical fields in the temporal and parietal lobe (Lund et al., 1975; Zeki, 1975, 1980; Shipp and Zeki, 1989) as well as pyramidal cells in layers $\mathrm{V}$ and VI, which project to subcortical targets such as the superior colliculus and lateral geniculate nucleus (Lund et al., 1975; Fries et al., 1985). Previous studies in the primary sensory and motor areas of monkeys, cats, and rats have identified classes of glutamate-immunoreactive pyramidal cells that project to cortical sites in the same hemisphere, to areas in the opposite hemisphere, and to subcortical targets (Conti et al., 1988a,b; Giuffrida and Rustioni, 1989a,b; Dori et al., 1992). Results from glutamate localization are supported by numerous biochemical and physiological studies, the implications of which are that corticofugal and corticocortical axon terminals release glutamate as a neurotransmitter (Baughman and Gilbert, 1981; Hicks et al., 1985; Tamura et al., 1990). The present findings of immunostained pyramidal cells in most layers of monkey area 17 are consistent with the previous studies, and suggest that several target-specific populations in this area are also likely to employ glutamate as a neurotransmitter.

Of the total population of neurons in monkey area 17, roughly half are found in layer IV (O'Kusky and Colonnier, 1982), and the great majority of these are spiny stellate cells (Mates and Lund, 1983). Distinguished from pyramidal cells by dendritic fields that lack prominent apical dendrites and by axons that are intrinsic to the cortex (Lund, 1973, 1988), spiny stellate cells in monkey visual cortex can be split into several groups based on differences in their sizes (Lund, 1973), thalamic inputs from magnocellular or parvocellular LGN (Hubel and Wiesel, 1972; Hendrickson et al., 1978), and local projections to adjacent layers (Lund, 1973; Fitzpatrick et al., 1985). Yet, from the physiological analyses of their synaptic effects (Mitzdorf and Singer, 1979) and the anatomical analyses of their morphology (LeVay, 1973; Mates and Lund, 1983; Saint-Marie and Peters, 1985), all spiny stellate neurons in monkey area 17 are considered to be excitatory. Cells through the full thickness of layer IVC are immunostained for glutamate. While the morphological features of these glutamate-positive cells were not evident in the immunostained material, the lack of GABA immunoreactivity within the glutamate cells and the paucity of pyramidal cells in layer IVC (Lund, 1973) leave only the spiny stellate cells as the class that is likely to display glutamate immunoreactivity in layer IVC. In addition, it is our qualitative judgement that the majority of neurons in layer IVC are glutamate immunoreactive since the double-labeling experiments indicate that glutamateimmunoreactive neurons exceed in number the layer IVC neurons that are GABA immunoreactive. These findings are in contrast with studies in other areas of cortex, including cat area 17 (Conti et al., 1989) and monkey first somatic sensory area (Conti et al., 1987), where fewer than $20 \%$ of the neurons in layer IV were determined to be glutamate immunoreactive. The data suggest that spiny stellate neurons vary in their neurotransmitter properties across areas of cortex and that monkey visual cortex stands out as an area in which most spiny stellate cells may use glutamate as a neurotransmitter.

Models of visual cortical circuitry and function divide neu- 
rons into nonoverlapping excitatory and inhibitory populations (Hubel and Wiesel, 1977; Szentagothai, 1978; Sillito, 1984; Martin, 1988). The neurotransmitter correlates of these two functional populations are often viewed as glutamate using and GABA using, respectively. Neurons immunoreactive for GABA and its synthesizing enzyme, GAD, make up one out of five neurons in monkey visual cortex (Fitzpatrick et al., 1987; Hendry et al., 1987). As with glutamate-immunoreactive neurons, the GABA cells are unevenly distributed and most densely packed in layers II-III, IVA, and IVC (Hendrickson et al., 1981; Fitzpatrick et al., 1987; Hendry et al., 1987). Since both GABA and glutamate populations are large and preferentially occupy the same layers of monkey visual cortex, the possibility remained that the two coexist in some neurons of this area. GABA/glutamate coexistence has been detected in rat first somatic sensory cortex (SI), which may reflect the close metabolic relationship between the two amino acids (Conti et al., 1987). However, results from the present study indicate that glutamate immunoreactivity is found in a neuronal population entirely separate from that displaying GABA immunoreactivity in monkey area 17. Thus, while glutamate-immunostained somata were frequently surrounded by GABA terminals, they were not themselves GABA immunoreactive. A similar lack of coexistence has been reported in the rat cortex for $P A G$ and markers specific for GABA neurons (Kaneko et al., 1992). The present data indicatc that cocxistence of immunocytochemically detectable levels of the principal cortical inhibitory and excitatory amino acids does not occur in monkey visual cortex.

Both glutamate and aspartate are amino acids that, when applied to cortical neurons, produce excitatory effects, consistent with a role for each as neurotransmitters of intrinsic neurons and afferent axons (Krnjevic and Phillis, 1963). The two share a common uplake system in the CNS (Logan and Snyder, 1971) and appear to be effective at the same receptor sites, but the available evidence suggests they are present within and released by separate groups of neurons. Immunoreactivity for glutamate and aspartate has been localized to different groups of neurons in rat SI (Giuffrida and Rustioni, 1989a,b) and V1 (Dori et al., 1992), and the two amino acids have separate patterns of release from cat visual cortex (Hicks et al., 1985; Tamura et al., 1990). Our findings do not directly address the existence of a separate population of excitatory neurons in monkey area 17 , but the presence of a significant number of neurons immunostained for neither glutamate nor GABA is compatible with the previously published data that such a population exists in the cortex.

\section{Organization of glutarnale-irnmunoreactive neurons and axons}

Glutamate-immunoreactive somata in monkey area 17 are densely distributed in layers and compartments containing geniculocortical terminations. These include layers IVC and VI and the regions of the $\mathrm{CO}$ patches in layers II-III. GABA neurons and receptors also follow closely the distribution of LGN afferents (Hendrickson et al., 1981; Fitzpatrick et al., 1987; Hendry et al., 1987, 1990; Benson et al., 1991). From these data it is apparent that both excitatory and inhibitory cortical neurons occupy preferentially the regions in which the first stages of visual processing occur in primate area 17 . Studies of ${ }^{3} \mathrm{H}-\mathrm{D}$ aspartate (Kisvarday et al., 1989) and ${ }^{3} \mathrm{H}$-GABA transport (Somogyi et al., 1981; DeFelipe and Jones, 1985) in monkey area 17 indicate that from these zones of geniculocortical terminations excitatory and inhibitory signals are relayed vertically to adjacent layers and horizontally to what are probably other columns.

Recent studies have focused on glutamate as a major neurotransmitter of thalamocortical axons. Physiological studies have shown that geniculocortical transmission in area 17 of cats is blocked by selective glutamate antagonists (Tsumoto et al., 1986; Hagihara et al., 1988; Shirokawa et al., 1989), while immunocytochemical studies have found thalamocortical neurons in rats and cats to express high levels of immunoreactivity for glutamate (Montero, 1990) or PAG (Kancko and Mizuno, 1988). Results from the present study suggest that axons and axon terminals are likely to make up the majority of immunostained neuropil elements in monkey area 17, particularly since the contribution by immunoreactive dendrites is restricted to primary shafts and to very few secondary branches. A major source of immunostained axons appears to be myelinated afferents: these are radially oriented processes surrounded by unstained cylinders, many of which could be traced from the white matter into layer IVC before they broke up into thinner branches. Our finding that the highest density of immunostained profiles is in layer IVC and in the regions of the CO puffs in layers II and III, both of which are innervated by geniculocortical axons, suggests that many of these myelinated immunoreactive axons in monkey area 17 arise from the LGN.

The source of glutamate-immunostained processes in the lacunac of laycr IVA is unknown, but they are not geniculocortical axons since these terminate in the lattice of layer IVA (Hendrickson et al., 1978). Immunostained processes in the lacunae may include a nongeniculate source of afferents or glutamateimmunoreactive intracortical axons. This difference in glutamate immunostaining of lattice walls and lacunae is an additional indication of the considerable differences in neurochemical properties expressed by neurons in the two parts of layer IVA, seen previously in the pattern of GABA terminals and receptors in this layer. Terminals immunoreactive for GAD (Fitzpatrick et al., 1987) and elements immunoreactive for the $\beta 2 / 3$ subunits of the $\mathrm{GABA}_{\mathrm{A}}$ receptor (Hendry et al., 1990) preferentially occupy the regions of the lattice, a pattern complementary to that for glutamate. These findings and other recent studies of neuronal elements in layer IV indicate layer IVA of monkey visual cortex is an amalgam of two different compartments (Peters and Sethares, $1991 \mathrm{a}, \mathrm{b}$; Hendry and Bhandari, 1992) in which differing physiological properties might be expected.

\section{Regulation of glutamate immunoreactivity}

Monocular deprivation by eye removal or intravitreal TTX injection in adult monkeys reduces histochemical and immunocytochemical staining for CO (Wong-Riley and Carroll, 1984; Hevner and Wong-Riley, 1990). In addition, markers of GABAergic neurotransmission are greatly reduced in cortical columns deprived of visual input (Hendry and Jones, 1986, 1988; Hendry et al., 1990; Benson et al., 1991). The results of the present study suggest that levels of glutamate also decline following monocular deprivation, and that these changes are most evident in layer IVC, the major geniculocortical recipient zone. Much of the reduction in neuropil immunostaining is likely to represent a decrease in intrinsic elements since the density of immunostained somata is obviously reduced, but loss of some glutamate immunostaining within geniculocortical axon terminals may also contribute to the reduction within deprivedeye columns.

Whereas the intensity of somatic immunostaining, as seen in 
bright field, was reduced precisely within the borders of deprived-eye columns, the intensity of neuropil immunostaining, detectable in dark field, was reduced only in the central threefourths of the deprived-eye columns. These findings are an additional indication that the central part of an ocular dominance column differs from its flanks in normal anatomical characteristics and in its response to visual deprivation. If, as we have suggested, the neuropil immunostaining in layer IVC is composed principally of axons, a continued normal intensity of immunoreactivity indicates that glutamate neurotransmission could be maintained at normal levels at the flanks of the deprivedeye columns. The source of such an axonal system is most likely intracortical, perhaps the axon collaterals of neurons in the neighboring columns, which are known to cross column borders (Katz et al., 1989).

Monocular deprivation in adult monkeys leads to an increase in immunocytochemically detectable levels of the enzyme CaM II kinase (Hendry and Kennedy, 1986; Benson et al., 1991). In monkey visual cortex, CaM II kinase is localized in the somata and dendrites of pyramidal cells in layers II-III, IVB, V, and VI, and in spiny stellate cells of layer IVC (Hendry and Kennedy, 1986). We interpret the similarity in CaM II kinase and glutamate localization to indicate that the two coexist in many of the same neurons. Thus, loss of input from one retina appears to reduce the level of glutamate immunoreactivity while increasing the level of CaM II kinase immunoreactivity in the same neurons. The data suggest that different regulatory mechanisms exist for these two substances in the same cortical cells.

What is the functional significance of reduced glutamate immunoreactivity within the deprived-eye columns? If the reduction in immunoreactivity is an accurate reflection of reduced glutamate neurotransmitter levels, a lower concentration of available transmitter would be expected. Whether such changes influence the synaptic physiology of neurons in the deprivedeye columns depends, among other factors, on the demand for transmitter release and the density of the postsynaptic receptors. One consequence of a possible reduction in glutamate neurotransmission is the loss of excitatory synaptic drive by interneurons and pyramidal cells in the center of the deprived-eye columns. Together with the likely reduction in inhibition, as evidenced by the decline in GABA and $\mathrm{GABA}_{\mathrm{A}}$ receptors in the deprived-eye columns (Hendry and Jones, 1986; Hendry et al., 1990), the reduction in excitation would leave the inputs from the normal eye to dominate the activity of the visual cortex. Such a change could contribute to the functional expansion of normal-eye columns in a monkey monocularly enucleated in adulthood (LeVay et al., 1980).

\section{References}

Akiyama H, Kaneko T, Mizuno N, McGeer PL (1990) Distribution of phosphate-activated glutaminase in the human cerebral cortex. $\mathbf{J}$ Comp Neurol 297:239-252.

Barbaresi P, Fabri M, Conti F, Manzoni T (1987) D- $\left[{ }^{3} \mathrm{H}\right]$ aspartate retrograde labelling of callosal and association neurones of somatosensory areas I and II of cats. J Comp Neurol 263:159-178.

Baughman RW, Gilbert CD (1981) Aspartate and glutamate as possible neurotransmitters in the visual cortex. J Neurosci 1:427-439.

Benson DL, Isackson PJ, Gall CM, Jones EG (1991) Differential effects of monocular deprivation on glutamic acid decarboxylase and type II calcium-calmodulin-dependent protein kinase gene expression in the adult monkey visual cortex. $J$ Neurosci 11:31-47.

Blasdel GG, Lund IS (1983) Termination of afferent axons in macaque striate cortex. J Neurosci 3:1389-1413.
Buhl EH, Singer W (1989) The callosal projection in cat visual cortex as revealed by a combination of retrograde tracing and intracellular injection. Exp Brain Res 75:470-476.

Carder RK, Jones EG, Hendry SHC (1991) Distribution of glutamate neurons and terminals in striate cortex of normal and monocularly deprived monkeys. Soc Neurosci Abstr 17:115.

Conti F, Rustioni A, Petrusz P, Towle AC (1987) Glutamate-positive neurons in the somatic sensory cortex of rats and monkeys. J Neurosci 7:1887-1901.

Conti F, Fabri M, Manzoni T (1988a) Glutamate-positive corticocortical neurons in the somatic sensory areas I and II of cats. J Neurosci 8:2948-2960.

Conti F, Fabri M, Manzoni T (1988b) Immunocytochemical evidence for glutamatergic cortico-cortical connections in monkeys. Brain Res 462:148-153.

Conti F, DeFelipe J, Fariñas I, Manzoni T (1989) Glutamate-positive neurons and axon terminals in cat sensory cortex: a correlative light and electron microscopic study. J Comp Neurol 290:141-153.

de Jong BM, Romijn HJ, Bujis RM (1987) Postembedding immunocytochemical GABA labeling in rat neocortex cultures: applicability in quantitative studies. Neurosci Lett 75:23-30.

DeFelipe J, Jones EG (1985) Vertical organization of $\gamma$-aminobutyric acid-accumulating intrinsic neuronal systems in monkey cerebral cortex. J Neurosci 5:3246-3260.

Donoghue JP, Wenthold RJ, Altschuler RA (1985) Localization of glutaminase-like and aspartate aminotransferase-like immunoreactivity in neurons of cerebral neocortex. $J$ Neurosci 5:2597-2608.

Dori I, Petrou M, Parnavelas JG (1989) Excitatory transmitter amino acid-containing neurons in the rat visual cortex: a light and electron microscopic immunocytochemical study. J Comp Neurol 290:169184.

Dori I, Dinopoulos A, Cavanagh ME, Parnavelas JG (1992) Proportion of glutamate- and aspartate-immunoreactive neurons in the efferent pathways of the rat visual cortex varies according to the target. J Comp Neurol 319:191-204.

Einstein G, Fitzpatrick D (1991) Distribution and morphology of area 17 neurons that project to the cat's extrastriate cortex. J Comp Neurol 303:132-149.

Farb C, Aoki C, Milner T, Kaneko T, LeDoux J (1992) Glutamate immunoreactive terminals in the lateral amygdaloid nucleus: a possible substrate for emotional memory. Brain Res 593:145-158.

Feldman ML (1984) Morphology of neocortical pyramidal neurons. In: Cerebral cortex, Vol l, Cellular components of the cerebral cortex (Peters A, Jones EG, eds), pp 123-200. New York: Plenum.

Fitzpatrick D, Lund JS, Blasdel GG (1985) Intrinsic connections of macaque striate cortex: afferent and efferent connections of lamina 4C. J Neurosci 5:3329-3349.

Fitzpatrick D, Lund JS, Schmechel DE, Towles AC (1987) Distribution of GABAergic neurons and axon terminals in the macaque striate cortex. J Comp Neurol 264:73-91.

Fosse VM, Heggelund P, Iversen E, Fonnum F (1984) Effects of area 17 ablation on neurotransmitter parameters in efferents to area 18 , the lateral geniculate body, pulvinar and superior colliculus in the cat. Neurosci Lett 52:323-328.

Fries W, Keizer K, Kuypers HGJM (1985) Large layer VI cells in macaque striate cortex (Meynert cells) project to both superior colliculus and prestriate visual area V5. Exp Brain Res 58:613-616.

Gabbott PLA, Somogyi P (1986) Quantitative distribution of GABAimmunoreactive neurons in the visual cortex (area 17) of the cat. Exp Brain Res 61:323-331.

Gilbert CD, Wiesel TN (1979) Morphology and intracortical projections of functionally characterized neurons in cat visual cortex. Nature 280:120-125.

Gilbert CD, Wiesel TN (1983) Clustered intrinsic connections in cat visual cortex. J Neurosci 3:1116-1133.

Giuffrida R, Rustioni A (1989a) Glutamatc and aspartate immunoreactivity in cortico-cortical neurons of the sensorimotor cortex of rats. Exp Brain Res 74:41-46.

Giuffrida R, Rustioni A (1989b) Glutamate and aspartate immunoreactivity in corticospinal neurons of rats. J Comp Neurol 288:154164.

Hagihara K, Tsumoto T, Sato H, Hata Y (1988) Actions of excitatory amino acid antagonists on geniculo-cortical transmission in the cat's visual cortex. Exp Brain Res 69:407-416.

Hendrickson AE, Wilson JR, Ogren MP (1978) The neuroanatomical 
organization of pathways between the dorsal lateral geniculate nucleus and visual cortex in old and new world primates. J Comp Neurol 182:123-136.

Hendrickson AE, Hum SP, Wu J-Y (1981) Immunocylochenical localization of glutamic acid decarboxylase in monkey striate cortex. Nature 292:605-607.

Hendry SHC, Bhandari MA (1992) Neuronal organization and plasticity in adult monkey visual cortex: immunoreactivity for microtubule associated protein 2 (MAP 2). Vis Neurosci 9:445-459.

Hendry SHC, Jones EG (1986) Reduction in number of GABA immunostained neurons in deprived-eye dominance columns of monkey area 17. Nature 320:750-753.

Hendry SHC, Jones EG (1988) Activity-dependent regulation of GABA expression in the visual cortex of adult monkeys. Neuron 1:701-712.

Hendry SHC, Kennedy MB (1986) Immunoreactivity for a calmodulin-dependent protein kinase is selectively increased in macaque striate cortex after monocular deprivation. Proc Natl Acad Sci USA 83:1536-1540.

Hendry SHC, Schwark HD, Jones EG, Yan J (1987) Numbers and proportions of GABA immunoreactive neurons in different areas of monkey cerebral cortex. J Neurosci 7:1503-1520.

Hendry SHC, Fuchs J, de Blas AL, Jones EG (1990) Distribution and plasticity of immunocytochemically localized $\mathrm{GABA}_{\mathrm{A}}$ receptors in adult monkey visual cortex. J Neurosci 10:2438-2450.

Hepler JR, Toomin CS, McCarthy KD, Conti F, Battaglia G, Rustioni A, Petrusz P (1988) Characterization of antisera to glutamate and aspartate. J Histochem Cytochem 36:13-22.

Hevner RF, Wong-Riley MTT (1990) Regulation of cytochrome oxidase protein levels by functional activity in the macaque monkey visual system. J Neurosci 10:1331-1340.

Hicks TP, Ruwe WD, Veale WL, Veenhuizen J (1985) Aspartate and glutamate as synaptic transmitters of parallel visual cortical pathways. Exp Brain Res 58:421-425.

Houser CR, Vaughn JE, Hendry SHC, Jones EG, Peters A (1984) GABA neurons in the cerebral cortex. In: Cerebral cortex, Vol 2, Functional properties of cortical cells (Jones EG, Peters A, eds), pp 63-90. New York: Plenum.

Hubel DH, Wiesel TN (1972) Laminar and columnar distribution of geniculocortical fibers in the macaque monkey. J Comp Neurol 146: $421-450$.

Hubel DH, Wiesel TN (1977) Functional architecture of macaque monkey visual cortex. Proc R Soc Lond [Biol] 198:1-59.

Hübener M, Schwarz C, Bolz J (1990) Morphological types of projection neurons in layer 5 of cat visual cortex. J Comp Neurol 301: 655-674.

Huettner JE, Baughman RW (1988) The pharmacology of excitatory synapses formed by identified corticocollicular neurons in primary cultures of rat visual cortex. J Neurosci 8:160-175.

Johnson RR, Burkhalter A (1992) Evidence for excitatory amino acid neurotransmitters in the geniculo-cortical pathway and local projections within rat primary visual cortex. Exp Brain Res 89:20-30.

Jones KA, Baughman RW (1988) NMDA- and non NMDA-receptor components of excitatory synaptic potentials recorded from cells in layer $\mathrm{V}$ of rat visual cortex. I Neurosci 8:3522-3534.

Kaneko T, Mizuno N (1988) Immunohistochemical study of glutaminase-containing neurons in the cerebral cortex and thalamus of the rat. J Comp Ncurol 267:590-602.

Kaneko T, Nakaya Y, Mizuno N (1992) Paucity of glutaminase-immunoreactive nonpyramidal neurons in the rat cerebral cortex. J Comp Neurol 322:181-190

Katz LC (1987) Local circuitry of identified projection neurons in cat visual cortex brain slices. J Neurosci 7:1223-1249.

Katz LC, Gilbert CD, Wiesel TN (1989) Local circuits and ocular dominance columns in monkey striate cortex. J Neurosci 9:13891399.

Kisvarday ZF, Cowey A, Smith AD, Somogyi P (1989) Interlaminar and lateral excitatory amino acid connections in the striate cortex of monkey. J Neurosci 9:667-682.

Krnjević K, Phillis JW (1963) Iontophoretic studies of neurones in the mammalian cerebral cortex. J Physiol (Lond) 165:274-304.

LeVay S (1973) Synaptic patterns in the visual cortex of the cat and monkey. Electron microscopy of Golgi preparations. J Comp Neurol 150:53-86.

LeVay S, Wiesel TN, Hubel DH (1980) The development of ocular dominance columns in normal and visually deprived monkeys. J Comp Neurol 191:1-51.

Livingstone MS, Hubel DH (1984) Anatomy and physiology of a color system in the primate visual cortex. J Neurosci 4:309-356.

Livingstone MS, Hubel DH (1987) Connections between layer 4B of area 17 and the thick cytochrome oxidase stripes of area 18 in the squirrel monkey. J Neurosci 7:3371-3377.

Logan WJ, Snyder SH (1971) Unique high affinity uptake systems for glycine, glutamic and aspartic acids in cerebral nervous tissue of the rat. Nature 234:297-299.

Lund JS (1973) Organization of neurons in the visual cortex, area 17, of the monkey (Macaca mulatta). J Comp Neurol 147:455-496.

Lund JS (1984) Spiny stellate cells. In: Cerebral cortex, Vol 1, Cellular components of the cerebral cortex (Peters A, Jones EG, eds), pp 255308. New York: Plenum

Lund JS (1988) Anatomical organization of macaque monkey striate visual cortex. Annu Rev Neurosci 11:253-288.

Lund JS, Lund RD, Hendrickson AE, Bunt AH, Fuchs AF (1975) The origin of efferent pathways from the primary visual cortex, area 17 , of the macaque monkey as shown by retrograde transport of horseradish peroxidase. J Comp Neurol 164:287-304.

Lund-Karlsen R, Fonnum F (1978) Evidence for glutamate as a neurotransmitter in the corticofugal fibres to the dorsal lateral geniculate body and the superior colliculus in rats. Brain Res 151:457-467.

Martin KAC (1988) From single cells to simple circuits in the cerebral cortex. Q J Exp Physiol 73:637-702.

Martin KAC, Whitteridge D (1984) Form, function and intracortical projections of spiny neurones in the striate visual cortex of the cat. $J$ Physiol (Lond) 353:463-504.

Mates SL, Lund JS (1983) Neuronal composition and development in lamina 4C of monkey striate cortex. J Comp Neurol 221:60-90.

Matute C, Streit P (1985) Selective retrograde labeling with $\mathrm{D}^{-}\left[{ }^{3} \mathrm{H}\right]$ aspartate in efferents to mammalian superior colliculus. J Comp Neurol 241:34-49.

Mitzdorf U, Singer W (1979) Excitatory synaptic ensemble properties in the visual cortex of the macaque monkey: a current source density analysis of electrically evoked potentials. J Comp Neurol 187:71-84.

Montero VM (1990) Quantitative immunogold analysis reveals high glutamate levels in synaptic terminals of retino-geniculate, corticogeniculate, and geniculo-cortical axons in the cat. Vis Sci 4:437-443.

Nishigori A, Tsumoto T, Kimura F (1990) Contribution of quisqualate/kainate and NMDA receptors to excitatory synaptic transmission in the rat's visual cortex. Vis Neurosci 5:591-604.

O'Kusky J, Colonnier M (1982) A laminar analysis of the number of neurons, glia and synapses in the visual cortex (area 17) of adult macaque monkeys. J Comp Neurol 210:278-290.

Ottersen OP, Storm-Mathisen J (1984) Neurons containing or accumulating transmitter amino acids. In: Handbook of chemical neuroanatomy, Vol 3, Classical transmitters and transmitter receptors in the CNS, Pt II (Björklund A, Hökfelt T, Kuhar MJ, eds), pp 141246. Amsterdam: Elsevier.

Ottersen OP, Storm-Mathisen J (1987) Localization of amino acid neurotransmitters by immunocytochemistry. Trends Neurosci 10:250255 .

Ottersen OP, Zhang N, Walberg F (1992) Metabolic compartmentation of glutamate and glutamine: morphological evidence obtained by quantitative immunocytochemistry in rat cerebellum. Neuroscience 46:519-534.

Peters A, Sethares C (1991a) Layer IVA of rhesus monkey primary visual cortex. Cereb Cortex 1:445-462.

Peters A, Sethares C (1991b) Organization of pyramidal neurons in area 17 of monkey visual cortex. J Comp Neurol 306:1-23.

Rakic P, Goldman-Kakic PS, Gallagher D (1988) Quantitative autoradiography of major neurotransmitter receptors in the monkey striate and extrastriate cortex. J Neurosci 8:3670-3690.

Saint-Marie RL, Peters A (1985) The morphology and synaptic connections of spiny stellate neurons in monkey visual cortex (area 17): a Golgi-electron microscopic study. J Comp Neurol 233:213-235.

Shaw C, Cynader M (1986) Laminar distribution of receptors in monkey (Macaca fascicularis) geniculostriate system. J Comp Neurol 248: 301-312.

Shaw C, Cameron L, March D, Cynader M, Zielinski B, Hendrickson A (1991) Pre- and postnatal development of GABA receptors in Macaca monkey visual cortex. J Neurosci 1 1:3943-3959.

Shipp S, Zeki S (1989) The organization of connections between areas 
V1 and V5 in macaque monkey visual cortex. Eur J Neurosci 1:309332.

Shirokawa T, Nishigori A, Kimura F, Tsumoto T (1989) Actions of excitatory amino acid antagonists on synaptic potentials of layer IV/ III neurons of the cat's visual cortex. Exp Brain Res 78:489-500.

Shupliakov O, Brodin L, Cullheim S, Ottersen OP, Storm-Mathisen J (1992) Immunogold quantification of glutamate in two types of excitatory synapse with different firing rates. J Neurosci 12:3789-3803.

Sillito AM (1984) Functional considerations of the operation of GABAergic inhibitory processes in the visual cortex. In: Cerebral cortex, Vol 2, Functional properties of cortical cells (Jones EG, Peters A, eds), pp 91-117. New York: Plenum.

Somogyi P, Cowey A, Halasz N, Freund TF (1981) Vertical organization of neurones accumulating ${ }^{3} \mathrm{H}-\mathrm{GABA}$ in visual cortex of rhesus monkey. Nature 294:761-763.

Somogyi P, Halasz K, Somogyi J, Storm-Mathisen J, Ottersen OP (1986) Quantification of immunogold labelling reveals enrichment of glutamate in mossy and parallel fibre terminals in cat cerebellum. Neuroscience 19:1045-1050.

Storm-Mathisen J, Leknes AK, Bore AT, Vaaland JL, Edminson P, Haug FS, Ottersen OP (1983) First visualization of glutamate and GABA in neurons by immunocytochemistry. Nature 301:517-520.

Streit $P$ (1980) Selective retrograde labeling indicating the transmitter of neuronal pathways. J Comp Neurol 191:429-463.

Streit $P$ (1984) Glutamate and aspartate as transmitter candidates for systems of the cerebral cortex. In: Cerebral cortex, Vol 2, Functional properties of cortical cells (Jones EG, Peters A, eds), pp 119-143. New York: Plenum.

Szentagothai J (1978) The neuron network of the cerebral cortex: a functional interpretation. Proc R Soc Lond [Biol] 201:219-248.

Tamura H, Hicks TP, Hata Y, Tsumoto T, Yamatodani A (1990) Release of glutamate and aspartate from the visual cortex of the cat following activation of afferent pathways. Exp Brain Res 80:447-455.

Tsumoto T (1990) Excitatory amino acid transmitters and their receptors in neural circuits of the cerebral neocortex. Neurosci Res 9:79102.

Tsumoto T, Masui H, Sato H (1986) Excitatory amino acid transmitters in neuronal circuits of the cat visual cortex. J Neurophysiol 55:469-483.

Watkins JC, Olverman HJ (1987) Agonists and antagonists for excitatory amino acid receptors. Trends Neurosci 10:265-271.

Wong-Riley MTT (1979) Changes in the visual system of monocularly sutured or enucleated cats demonstrable with cytochrome oxidase histochemistry. Brain Res 171:11-28.

Wong-Riley M, Carroll EW (1984) Effect of impulse blockage on cytochrome oxidase activity in monkey visual system. Nature 307:262264.

Zeki SM (1975) The functional organization of projections from striate to prestriate visual cortex in the rhesus monkey. Cold Spring Harbor Symp Quant Biol 40:591-600.

Zeki S (1980) A direct projection from area Vl to area V3A of rhesus monkey visual cortex. Proc R Soc Lond [Biol] 207:499-506. 